\title{
Coagulation Measurement and Optimisation in Cardiac Surgery
}

\author{
Philip Johnson and Andrew Westbrook \\ Department of Anaesthesia, Intensive Care and Pain Medicine, \\ St Vincent's University Hospital, Elm Park, Dublin
}

Ireland

\section{Introduction}

Coagulation is a complex physiological balancing mechanism that maintains haemostasis when blood vessels are injured. A hypercoaguable state as seen in early sepsis, cancer or pregnancy can cause arterial and/or venous obstruction with disruption of blood-flow and end organ damage. Similarly a hypocoaguable state can cause catastrophic haemorrhage and lead to death.

Up to $20 \%$ of all blood transfusions in the USA are related to cardiac surgery (1). The pathogenesis of coagulopathy in this patient group is multifactorial: patients are older (2), and more complex and this is reflected in the number of redo surgeries and the concomitant use of agents such as clopidogrel, aspirin, coumarin anticoagulants and heparins. Also cardiopulmonary bypass activates the coagulation system with an initial hypercoaguable state and platelet activation, followed by factor and platelet consumption. Hypothermia, acidosis, hypocalcaemia and the dilutional effects of circuit priming all increase the risk of bleeding (3).

Platelet transfusion per se in the perioperative period has been associated with an increased risk of serious adverse events (4). Indeed both red cell and platelet transfusion have been shown to have a negative risk-adjusted effect on health-related quality of life after cardiac surgery (5). The haemostatic status of a patient undergoing cardiopulmonary bypass can change very quickly because of haemorrhage or the use of high dose heparin or protamine and as such blood component administration in cardiac surgery can often be empiric. This is compounded by the limited utility of the standard coagulation tests, which have a slow turnaround time in a setting where there can be rapid changes in coagulation status.

All patients presenting for cardiac surgery will be anticoagulated in the perioperative period, either for cardiac or non-cardiac reasons, and an appropriate balance needs to be struck between minimising perioperative blood loss and use of homologous blood products, and avoiding pathological thrombosis.

Coagulation status can be measured by means of laboratory tests or near-patient tests (also referred to as point-of-care tests). Effective use and interpretation of these tests can guide physicians and surgeons alike in the use of medications and homologous blood products and timely intervention of surgery to optimise patient outcomes. Indeed, the thromboelastogram (TEG), a point-of-care test, should discriminate "surgical" from "medical" causes of bleeding in this population thus reducing unnecessary transfusions and allowing timely return to the operating room for definitive treatment. The TEG will also 
facilitate targeted therapy in a "medically" bleeding patient by providing information about platelet function and degree of fibrinolysis as well as factors produced in the liver. Standard coagulation tests and point-of-care tests will be discussed in detail with reference to their individual utility in this group of patients.

\section{Coagulation pathways}

Coagulation requires complex interactions of cellular and molecular components, mainly involving platelets, plasma and red blood cells. The process was classically described as a cascade of 'Intrinsic', 'Extrinsic', and 'Common' pathways (see Figure 1). These pathways

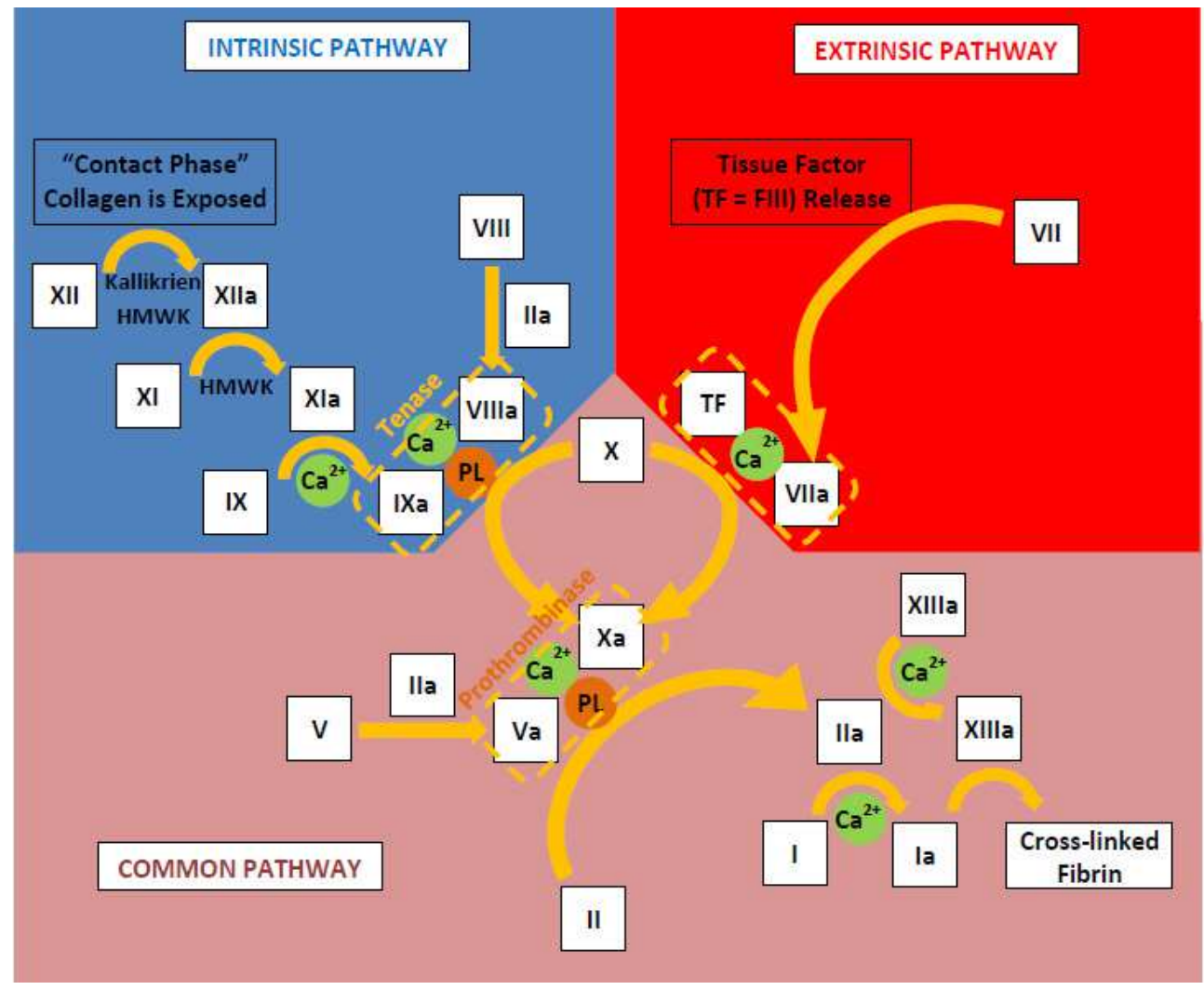

The Intrinsic Pathway is activated when FXII binds to exposed collagen of damaged endothelium. The cascade of activations occur as shown, and amplification also occurs (for example FXIIa converts prekallikrien to kallikrien and auto-activates more FXII). The resulting "Tenase" complex (shown in a dashed yellow line) activates FX. The Extrinsic Pathway is initiated by Tissue Factor, and results in a TF/FVIIa complex (in a dashed yellow line) that activates FX. The Common Pathway yields thrombin (FIIa), which not only activates Fibrinogen (FI) but also amplifies other stages of the cascade by activating FVIII, FV and FXIII. The ultimate result is a cross-linked Fibrin mesh. HMWK = High Molecular Weight Kininogen. PL = Phospholipid.

Fig. 1. The Classic Coagulation Cascade Model(6). 
are useful in terms of interpreting some of the coagulation tests, but in vitro coagulation is less linear and occurs by a combination of these pathways. Current understanding of the coagulation process is best described by the cell-based model.

The coagulation factors were discovered in the 1940s and 1950s. They are proenzymes found in plasma, which are converted to active enzymes during the coagulation process. The factors were assigned roman numerals in the order they were discovered; each factor also has one or more names. The more commonly used ones are shown in the figure 2 (6). The numerals are prefixed by " $\mathrm{F}$ " for "factor", and the suffix " $\mathrm{a}$ " is used to indicate the activated form of the factor.

\begin{tabular}{|l|l|}
\hline I & Fibrinogen \\
\hline II & Prothrombin \\
\hline IIa & Thrombin \\
\hline III & $\begin{array}{l}\text { Tissue Factor / Tissue Thromboplastin (sometimes excluded from the list of factors - } \\
\text { not actually a plasma proenzyme, but an integral membrane protein, which is a } \\
\text { receptor for FVII) }\end{array}$ \\
\hline IV & Calcium ions \\
\hline V & Labile Factor / Proaccelerin / accelerator (AC-) globulin \\
\hline VI & Factor Va was once known as FVI \\
\hline VII & $\begin{array}{l}\text { Serum Factor / Stable Factor / Proconvertin / Serum Prothrombin Conversion } \\
\text { Accelerator (SPCA) / Cothromboplastin / Autoprothrombin I }\end{array}$ \\
\hline VIII & $\begin{array}{l}\text { Haemophilia A factor / antihaemophiliac Factor / Plasma Thromboplastic Factor / } \\
\text { Thromboplastinogen / Platelet Cofactor }\end{array}$ \\
\hline IX & Haemophilia B Factor / Christmas Factor / Plasma Thromboplastin Component \\
\hline X & \multicolumn{2}{|l|}{} \\
\hline XI & Haemophilia C factor / Plasma Thromboplastin Antecedent (PTA) \\
\hline XII & Hageman Factor / Contact Factor \\
\hline XIII & Fibrin Stabilizing Factor \\
\hline
\end{tabular}

Fig. 2. Factor Numbers and Common name(s) - anomalies are shown in green

\section{Intrinsic pathway}

The "Intrinsic Pathway", so-called because its components are all present within whole blood, is initiated when blood comes in contact with a negatively charged surface such as glass or the surface of an activated platelet. It consists of a reaction cascade involving FXII, High Molecular Weight Kininogen (HMWK), prekallikrien, FXI, FIX, FIIa, FVIII, and $\mathrm{Ca}^{2+}$ and culminates in the activation of FX at the Common Pathway. The activated partial thromboplastin time (APTT) laboratory test measures the intrinsic pathway.

\section{Extrinsic pathway}

The "Extrinsic Pathway" is initiated when endothelial injury causes tissue factor (TF, or FIII) to come into contact with FVII. TF non-proteolytically activates FVII. The FVIIa/TF complex then activates FX. The extrinsic pathway can be measured by the Prothrombin Time (PT) laboratory test. 


\section{The common pathway}

The intrinsic and extrinsic pathways both lead to activation of FX. FXa, FVa and $\mathrm{Ca}^{2+}$ activate prothrombin (FII) to form thrombin (FIIa). Thrombin has several actions: it activates fibrinogen (FI) to yield fibrin monomers; it amplifies the coagulation process by activating further prothrombin, FV and FVIII; it activates FXIII whose active form promotes cross-linking of fibrin monomers to form stable polymers; (as discussed later in the cell-based model, it also participates in processes that temper coagulation to avoid overwhelming pathological thrombosis.) The common pathway thus yields a mesh of covalently cross-linked fibrin strands and entrapped red blood cells, which form a stable blood clot. Disorders of the common pathway will affect tests of the intrinsic and extrinsic pathways.

\section{The cell-based model}

The five steps of this model are initiation, amplification, propagation, stabilisation and inhibition of further coagulation (7). In health, $1 \%$ of circulating FVII is in the active form.
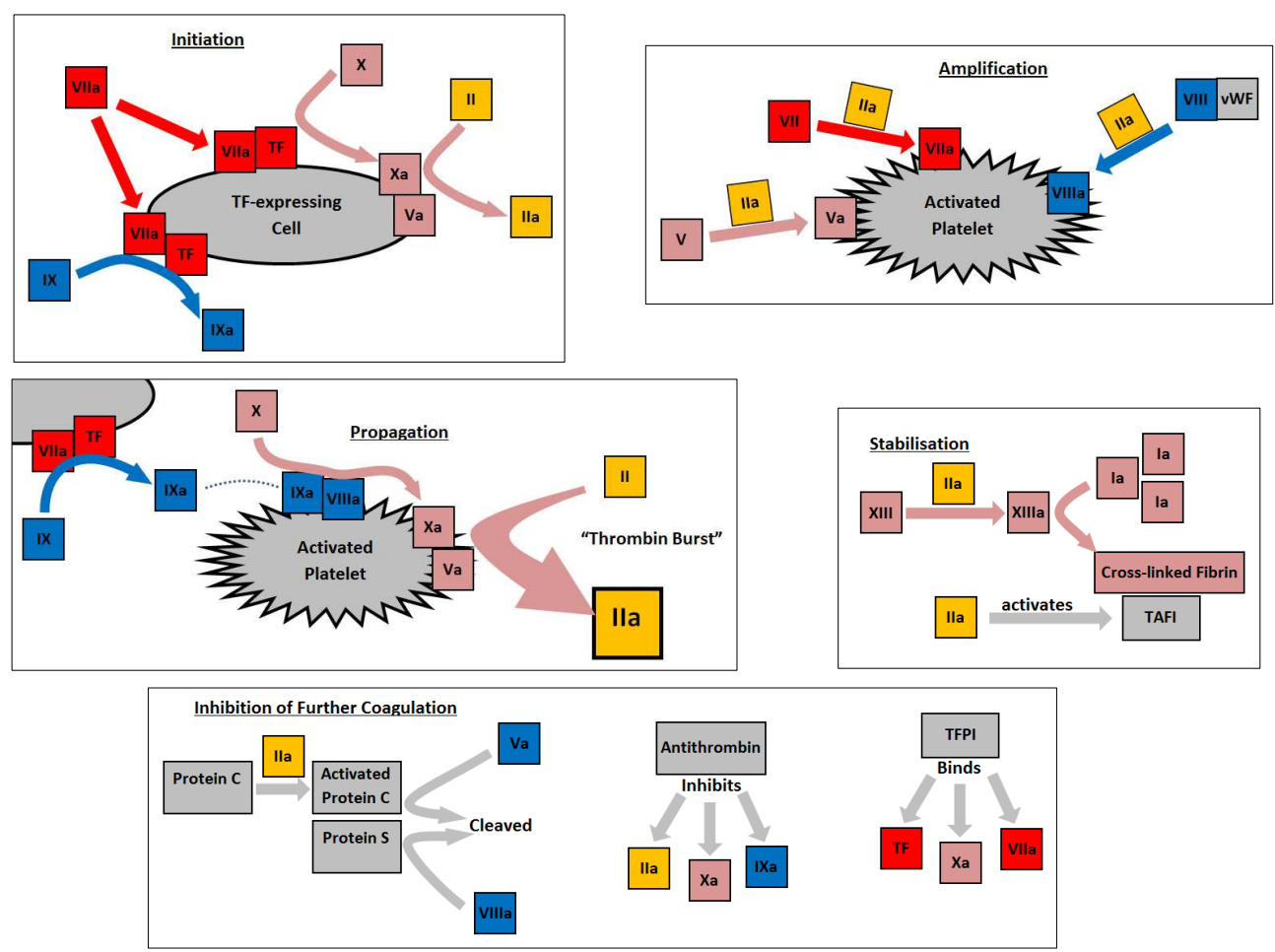

Blue, Red and Purple correspond respectively to Intrinsic, Extrinsic and Common Pathways of the Classic Coagulaton Cascade. Thrombin has a key role throughout, hence is shown in yellow. TF = Tissue Factor. $\mathrm{vWF}=$ von Willebrand Factor. TAFI $=$ Thrombin Activated Thrombolysis Inhibitor. TFPI = Tissue Factor Pathway Inhibitor.

Fig. 3. The Cell-Based Model of Coagulation 
- At 'initiation', TF binds to circulating FVIIa and acts with FV to generate FIXa and FXa. The FXa converts a small amount of FII to thrombin.

- During 'amplification' this thrombin triggers reactions on the surface of activated platelets, where more FVIIa is produced. Thrombin activates co-factors FV and FVIII. These active factors facilitate the sequence of thrombin-producing reactions.

- In 'propagation', the TF/FVIIa complex continues to activate FIX and the FIXa/FVIIIa ("tenase") complex generates more FXa to drive a continuous "thrombin burst".

- In 'stabilisation', FXIII is activated by high levels of thrombin and polymerises the fibrin monomers to complete the clot. Thrombin-activated Fibrinolysis Inhibitor contributes to clot stability.

- Pathological thrombosis is prevented by regulation of the coagulation process. 'Inhibition of further coagulation' occurs via activated protein $\mathrm{C}(\mathrm{aPC})$, protein $\mathrm{S}$, tissue factor pathway inhibitor (TFPI) and antithrombin. Thrombin activates protein $C$, which cleaves FVa and FVIIIa with Protein S acting as a cofactor. TFPI binds TF/FVIIa and FXa in a quaternary complex. Antithrombin inhibits thrombin, FIXa and FXa. $(8,9)$

\section{Platelet function in haemostasis}

Platelets respond to vascular wall damage by adhesion, aggregation, release of granule content and morphological changes. Von Willebrand Factor is a plasma protein that acts as a bridge between platelets and the exposed collagen of damaged tissue. The platelet binding site is the membrane glycoprotein GPIb-VIX. Von Willebrand Factor also acts as a carrier protein for, and stabiliser of FVIII, preventing premature proteolytic degradation by Protein C.

\section{Coagulation pathology}

\section{Hypercoagulability / Thrombophilia}

A hypercoagulable state can predispose a patient to deep vein thrombosis (DVT), pulmonary embolism (PE), stroke, and recurrent miscarriage. Causes include disorders of platelets, vessel walls, systemic disease and well as genetic and environmental factors (10).

\section{Haemophiliae and other Bleeding Diatheses}

Disorders of coagulation factors tend to present with haemarthroses and muscle haematomas. Patients with platelet disorders more commonly present with skin bruising, epistaxis or menorrhagia. Von Willebrand's Disease is the most common inherited coagulopathy; other forms are rare, apart from Haemophilia A and B. The most common acquired coagulation disorders are disseminated intravascular coagulation (DIC), liver disease and vitamin $\mathrm{K}$ deficiency although disorders discussed elsewhere in this chapter are more common in the setting of cardiac surgery.

\section{Anticoagulant drugs}

These drugs are used to prevent thrombus formation, or limit the extension of existing thrombus. Venous thrombus consists of a fibrin web with trapped platelets and erythrocytes and is more successfully treated or prevented with anticoagulants than arterial thrombus, which contains proportionally more platelets and less fibrin. 


\begin{tabular}{|c|c|}
\hline Source & Hypercoagulable risk factor (mechanism and notes in brackets) \\
\hline Blood & $\begin{array}{l}\text { Protein } S \text { and Protein C deficiencies (these normally regulate } \\
\text { coagulation) } \\
\text { Polycythaemia rubra vera, Thrombocytosis (blood is more viscous } \\
\text { thus prone to stasis - treatment may include bone marrow } \\
\text { suppression) } \\
\text { Paroxysmal Nocturnal Haemoglobinuria (excessive RBC sensitivity } \\
\text { to complement) } \\
\text { Prothrombin } 20210 \text { mutation (leads to increased prothrombin levels) } \\
\text { Heparin Induced Thrombocytopenia (heparin-associated antibodies } \\
\text { develop) } \\
\text { Antithrombin III deficiency (incidence } 1 \text { in } 5000 \text { ) } \\
\text { Inherited dysfibrinogenaemia (rare) } \\
\text { Leiden Factor V mutation - the most common hereditary cause of } \\
\text { hypercoagulable state (anticoagulant effect of activated protein C is } \\
\text { ineffective against mutated factor V) } \\
\text { Thalassaemia } \\
\text { Sickle Cell Disease }\end{array}$ \\
\hline Systemic & $\begin{array}{l}\text { Pregnancy / postpartum } \\
\text { Iatrogenic Oestrogen (increases coagulation factors and reduces } \\
\text { anticoagulant effect of antithrombin III) } \\
\text { Sepsis (increased circulating tissue factor) } \\
\text { Hyperhomocysteinaemia (genetic disorder, treated with folate, } \\
\text { vitamin } \mathrm{B}_{6} \text { \& vitamin } \mathrm{B}_{12} \text { ) } \\
\text { Smoking (mechanisms include endothelial damage and platelet } \\
\text { adhesion) } \\
\text { Congestive Heart Failure (mechanisms include vascular endothelial } \\
\text { dysfunction \& increased fibrinogen) } \\
\text { Antiphospholipid syndrome, including lupus anticoagulant (either } \\
\text { primary or secondary to infection, drugs, malignancy) } \\
\text { Uraemia (endothelial dysfunction, increased cytokines) } \\
\text { Surgery (reduced risk with thromboprophylactic drugs } \\
\text { perioperatively) } \\
\text { Diabetes mellitus (increased platelet activation) } \\
\text { Hyperlipidaemia } \\
\text { Obesity } \\
\text { Malignancy (tumour cells activate clotting cascade and inhibit } \\
\text { fibrinolysis) } \\
\text { Trauma/burns (release of tissue thromboplastin) } \\
\text { Immobility (blood stasis) } \\
\text { Hyperthyroidism (increase in circulating FX) } \\
\text { Hypothyroidism (increased circulating fibrinogen, FVII) }\end{array}$ \\
\hline
\end{tabular}

Fig. 4. Causes of a Hypercoagulable State (11) 


\begin{tabular}{|c|c|}
\hline Inherited Bleeding Disorders & Notes \\
\hline Von Willebrand Disease (vWD) & $\begin{array}{l}\text { Autosomal dominant, affects } 1 \% \text { of population. Von } \\
\text { Willebrand Factor (vWF) can be deficient, defective or } \\
\text { completely absent. vWF allows platelets to adhere to } \\
\text { damaged endothelium and also stabilises circulating } \\
\text { FVIII. Severe vWD can therefore cause FVIII deficiency. } \\
\text { Desmopressin raises vWF in mild disease, in more severe } \\
\text { disease FVIII/vWF concentrate may be required. }\end{array}$ \\
\hline Haemophilia A = FVIII deficiency & $\begin{array}{l}\text { Inherited, X-linked recessive (affecting males). Severe } \\
\text { coagulation disorder. FVIII concentrate is given } \\
\text { prophylactically in profound deficiency, and as required } \\
\text { in milder forms of the disease. }\end{array}$ \\
\hline Haemophilia B = FIX deficiency & $\begin{array}{l}\text { Severe coagulation disorder, also X-linked, clinically } \\
\text { indistinguishable from Haemophilia A. }\end{array}$ \\
\hline Thrombocytopenia & $\begin{array}{l}\text { May be due to primary bone marrow dysfunction, } \\
\text { autoimmune disease, or a consequence of other disease } \\
\text { processes or drugs. }\end{array}$ \\
\hline FXI deficiency & Patients exhibit a variable bleeding disorder \\
\hline \multicolumn{2}{|l|}{ Factor V deficiency } \\
\hline $\begin{array}{l}\text { Structural problems with blood } \\
\text { vessels }\end{array}$ & $\begin{array}{l}\text { Disorders such as Haemorrhagic Telangiectasia and } \\
\text { Ehlers-Danlos syndrome }\end{array}$ \\
\hline Acquired Bleeding Disorders & Notes \\
\hline DIC & $\begin{array}{l}\text { Pathological activation of coagulation from triggers such } \\
\text { as sepsis, malignancy, burns, or obstetric emergencies. } \\
\text { Widespread microvascular thrombosis leads to } \\
\text { consumption of clotting factors and platelets which is } \\
\text { followed by bleeding. Increased Fibrin Degradation } \\
\text { Products (FDPs) may also impair coagulation. High } \\
\text { mortality, primarily from complications of microvascular } \\
\text { thrombosis. Fresh frozen plasma and platelets are given } \\
\text { whilst underlying trigger is addressed. }\end{array}$ \\
\hline Liver Disease & $\begin{array}{l}\text { Synthesis of coagulation factors is affected. Portal } \\
\text { hypertension can also lead to splenomegaly with } \\
\text { sequestration of platelets and resultant } \\
\text { thrombocytopenia }\end{array}$ \\
\hline Vitamin K Deficiency & $\begin{array}{l}\text { Can occur with malabsorption of this fat-soluble vitamin } \\
\text { in obstructive jaundice. Deficiency of FII, FVII, FIX, FX } \\
\text { occurs }\end{array}$ \\
\hline Thrombocytopenia & $\begin{array}{l}\text { May be due to primary bone marrow dysfunction, } \\
\text { autoimmune disease, or a consequence of other disease } \\
\text { processes or drugs. }\end{array}$ \\
\hline Platelet dysfunction & $\begin{array}{l}\text { Disorders of platelet granules can occur in } \\
\text { myelodysplastic disease, haematological malignancy, } \\
\text { uraemia or liver disease. Antiplatelet drugs are also } \\
\text { discussed in this chapter. }\end{array}$ \\
\hline HELLP syndrome & $\begin{array}{l}\text { A severe variant of preeclampsia characterised by } \\
\text { Haemolysis, Elevated Liver enzymes, and Low Platelets }\end{array}$ \\
\hline Allergic purpura & Inflammation of small blood vessels with leakage \\
\hline
\end{tabular}




\section{Thrombin inhibitors}

Thrombin (FIIa) is central to the coagulation process. It usually converts soluble fibrinogen to fibrin, stimulates platelets and activates FV, FVIII, FXI and FXIII. Thrombin inhibitors can work directly on FIIa, or indirectly by preventing activation of FII.

Heparin is long-established as an anticoagulant, which facilitates endogenous antithrombin to decrease activation of FII. The indirect mechanism has limited activity against thrombin that is bound to fibrin or fibrin degradation products (FDPs). In contrast, direct-acting thrombin inhibitors (DTIs) inhibit bound, as well as free, FIIa.

Heparin remains the most widely used drug in this class, but other agents are being investigated that may offer increased efficacy or a more favourable side-effect profile. Thrombin inhibitors may also have administrative advantages over heparin if they can be given orally and if anticoagulation monitoring is unnecessary.

\section{Indirect thrombin inhibitors}

\section{Heparin}

Heparin is found in the liver and mast cell granules. Commercial heparin is extracted from bovine or porcine sources and is a mixture of acid mucopolysaccharides with molecular weights ranging from 3000 to 60,000 daltons. It is available in this unfractionated form and also as various low-molecular weight preparations. Heparin reversibly binds to antithrombin III, thereby enhancing inhibition of FIX, FX, FXI, FXII, FXIII, thrombin and also plasmin. At high concentrations heparin also inhibits platelet aggregation.

Unfractionated heparin is given intravenously or subcutaneously and is also used to anticoagulate the cardiopulmonary bypass circuit in cardiac surgery. Intravenous doses are titrated to a target range of ACT or APTT. The biological half-life is $1 \mathrm{hr}$ at physiological temperature but longer at lower temperatures during cardiopulmonary bypass. Heparin effects are reversed by protamine, a base that forms a stable, inactive salt complex with the acidic heparin.

Low-molecular weight heparin preparations have an average molecular weight below 8000 daltons. They are more effective at inhibiting factor Xa than unfractionated heparin, with less of an effect on thrombin. Their longer half-life and more predictable pharmacokinetic profile make them suitable for once-daily subcutaneous dosing without routine coagulation monitoring. APTT is not altered by LMWH so if monitoring is needed, anti-Xa levels are measured; this is useful for patients with renal impairment or at extremes of weight. LMWH effects cannot be reversed with protamine.

Side-effects of heparin can include hyperkalaemia and Heparin-induced Thrombocytopaenia (HIT). HIT has a frequency of $2.6 \%$ when unfractionated heparin is used, and $0.2 \%$ with LMWH (12). The most severe form of HIT is immune-mediated and can be complicated by thrombosis. Platelet counts should therefore be monitored in patients receiving heparin. If HIT occurs, heparin should be discontinued and an alternative anticoagulant used to reduce the risk of thrombosis. Warfarin should not be given to patients with HIT because of the high risk of warfarin necrosis, so alternatives such as lepirudin or danaparoid are chosen. A screening test for antibodies is the initial investigation when HIT is suspected. Patients testing positive proceed to the more specific serotonin release assay.

For post-CPB reversal of heparin, protamine sulphate is used. $1 \mathrm{mg}$ of protamine neutralises the effect of 100 i.u of unfractionated heparin, by combining with heparin to form an 
inactive salt compound. Protamine acts within 5 minutes and can last for 2 hours. Effective protamine reversal is confirmed when the ACT returns to the baseline value.

Excess administration of protamine is undesirable, as it has its own intrinsic anticoagulant effect at high doses. It should be given slowly to minimise cardiovascular side-effects (systemic arterial vasodilatation and pulmonary arterial vasoconstriction), and the maximum administration rate in adults is $50 \mathrm{mg}$ per 10 minute period.

Protamine can only partially reverse the anticoagulant effect of LMWH.

\section{Other indirect thrombin inhibitors}

Warfarin reduces hepatic synthesis of FII. Factor Xa inhibitors will reduce activation of FII. These agents are considered by some sources to be indirect thrombin inhibitors and are covered elsewhere in this chapter.

\section{Direct thrombin inhibitors}

This class includes Dabigatran, Argatroban, Bivalirudin, the recombinant Hirudins (eg lepirudin and desirudin) and also Melagatran and its prodrug Ximelagatran.

Dabigatran is a direct thrombin inhibitor, taken orally, which is being increasingly used in prevention of thromboembolism following lower limb joint replacement surgery. Dabigatran is also gaining a role in prevention of embolic stroke in patients with atrial fibrillation. The predictable pharmacokinetic profile allows a fixed-dose regimen to be used without routine coagulation monitoring. Dabigatran cannot be reversed. It should be discontinued at least $24 \mathrm{hrs}$ before elective surgery. In the event of life-threatening haemorrhage, non-specific prohaemostatic agents such as recombinant factor VIIa and prothrombin concentrate complexes could be considered; accelerated clearance using haemofiltration or charcoal filtration has also been suggested (13).

Argatroban is given intravenously and has a role in prevention/treatment of thrombosis and during Percutaneous Coronoary Interventions (PCI) in patients with HIT. It is metabolised hepatically so may be more appropriate than Lepirudin for patients with renal impairment. Its effect can be monitored by APTT.

Hirudins are direct thrombin (FIIa) inhibitors derived from chemicals found in leech saliva. Lepirudin and Desirudin are recombinant agents. Lepirudin is used to anticoagulate patients with HIT. It is given intravenously, titrated according to APTT(14), and cleared renally. Desirudin can be given subcutaneously to prevent thromboembolism.

Bivalirudin is a hirudin analogue, and can be used in combination with antiplatelet agents for patients undergoing percutaneous coronary intervention (PCI). It can be titrated according to ACT(14). Thrombin function recovers to normal approximately $1 \mathrm{hr}$ after Bivalirudin infusion is discontinued.

Melagatran and its prodrug Ximelagatran were withdrawn from the market after the EXTEND trial found potential risk of severe liver injury (15).

\section{Factor $\mathrm{Xa}$ inhibitors}

The synthetic pentasaccharide Fondaparinux is an indirect FXa inhibitor, with structural similarities to heparin. It works by facilitating antithrombin III (AT) activity, and is therefore dependent on AT for its effect (16). Fondaparinux is given subcutaneously for prevention/treatment of venous thromboembolism, and for acute coronary syndrome. In patients with normal renal function, anticoagulation effects persist for 2-4 days after discontinuation of Fondaparinux. There is no antidote available to reverse the effect of 
Fondaparinux. It does not affect PT, APTT or ACT. Although monitoring is not routinely required in healthy patients, it can be achieved by an anti-FXa assay.

Newer orally-administered drugs Rivaroxiban and Apixaban are direct FXa inhibitors. They have similar indications to Fondaparinux.

\section{Heparinoids}

Danaparoid is produced from the same porcine material as heparin, but all heparin and heparin fragments are extracted. It catalyses AT-mediated inhibition of FXa and, to a lesser extent, FIIa (17). It has been used to anticoagulate patients with HIT. There can be crossreactivity so patients should continue to have platelet count monitored (18). Coagulation monitoring, if required, is by anti-Xa assay. It is not reversed by protamine.

Warfarin

This oral agent is used to minimise the risk of embolic stroke in patients with valvular heart disease or arrhythmia, and to prevent/treat venous thromboembolism. It inhibits the hepatic synthesis of vitamin K-dependent coagulation factors (FII, FVII, FIX, FX) as well as proteins C, $S$ and $Z$ (19). It takes at least $48 \mathrm{hrs}$ to develop the anticoagulant effect, during which time the inhibition of proteins $C$ and $S$ may paradoxically create a prothrombotic state, hence heparin is usually added during warfarin introduction. Warfarin effect is titrated using PT or INR tests with target ranges shown in the table. Additional or alternative agents may be recommended in valvular or structural heart disease (20).

Perioperatively, warfarin is only continued for certain procedures with low risk of bleeding. Warfarin is usually held 5 days prior to surgery with INR $\leq 1.5$ confirmed immediately preop. A shorter-acting anticoagulant, such as LMWH, can be given as bridging anticoagulant therapy until shortly before surgery and continued once haemostasis has been obtained. The decreased risk of thrombosis or embolism by using bridging anticoagulation is weighed against the increased risk of haemorrhage. Decisions regarding perioperative anticoagulation are made on an individual patient basis (22).

\begin{tabular}{|l|l|}
\hline \multicolumn{1}{|c|}{ Warfarin Indication } & \multicolumn{1}{c|}{ Target INR (+/- 0.5) } \\
\hline Atrial fibrillation, DVT, PE & 2.5 \\
\hline Recurrent DVT/PE despite INR >2 & 3.5 \\
\hline For Cardioversion in Atrial Fibrillation & $\begin{array}{l}3.0 \text { for } \geq 3 \text { weeks prior, and } 2.5 \text { for } \\
\geq 4 \text { weeks post-Cardioversion }\end{array}$ \\
\hline $\begin{array}{l}\text { Mechanical Prosthetic Heart Valves: } \\
\text { Individualised targets based on: (a) thrombogenic } \\
\text { risk of the valve type and position, (b) patient- } \\
\text { related risk factors for thrombosis and haemorrhage } \\
(20,21) .\end{array}$ & $\begin{array}{l}\text { Typically 3 for aortic valves, } \\
3.5 \text { for mitral valves. }\end{array}$ \\
\hline $\begin{array}{l}\text { Bioprosthetic Valves } \\
\text { (20) }\end{array}$ & $\begin{array}{l}\text { 2.5 for 3 months post-insertion, } \\
\text { after which consider } \\
\text { discontinuation if no other risk } \\
\text { factors }\end{array}$ \\
\hline
\end{tabular}

INR = International Normalised Ratio, DVT = Deep Venous Thrombosis, PE = Pulmonary Embolism (22)

Fig. 5. INR targets. 
In the event of major haemorrhage in a patient who is anticoagulated with warfarin, it may be necessary to discontinue warfarin, administer vitamin K 5-10mg (phytomenadione), and in some cases replace the deficient coagulation factors using prothrombin complex concentrate 30-50 units/kg (containing FII, FVII, FIX, FX) or fresh frozen plasma 10$15 \mathrm{ml} / \mathrm{kg}$.

\section{Antiplatelet agents}

These agents have a variety of mechanisms of action as shown in the table. Decisions regarding perioperative discontinuation of these medications are made on an individual patient basis. As with other anticoagulants, continuation increases perioperative bleeding but withholding the agent increases risk of thrombosis. The risk of withholding antiplatelet agents in the setting of acute coronary syndrome generally outweighs the benefits so they are usually continued in this context (23).

\section{Prostacyclins}

Epoprostenol is a prostacyclin that can be infused to treat pulmonary hypertension, or to inhibit platelet aggregation during renal dialysis.

\section{Antifibrinolytic Agents}

Aprotinin, tranexamic acid and aminocaproic acid are antifibrinolytic agents, which can be used to decrease peri-operative bleeding. Aprotinin is a naturally-occurring serine protease inhibitor, and the other two agents are lysine analogues. Studies have shown reduction in blood loss and transfusion requirements with the use of these agents, particularly in patients taking antiplatelet agents perioperatively $(25,26)$.

Aprotinin was associated with increased incidence of death, cerebrovascular accidents and renal events in an observational study of patients undergoing revascularisation surgery (27). These effects were not seen with tranexamic acid or $\varepsilon$ aminocaproic acid. Indeed a prior meta-analysis of aprotinin use in patients undergoing cardiopulmonary bypass suggested it was safe (28). The current recommendation is to reserve aprotinin use for patients at the highest risk of bleeding complications (29).

\section{Laboratory coagulation tests}

\section{Platelet count}

The normal range is $150-400 \times 10^{9} / \mathrm{L}$. Thrombocytopenia can occur as a result of decreased bone marrow production or excessive destruction. Typically, traumatic bleeding, purpura and easy bruising occur at platelet counts less than $50 \times 10^{9} / \mathrm{L}$; spontaneous bleeding may occur at platelet counts below $20 \times 10^{9} / \mathrm{L}$. There is not a strong evidence base for a transfusion trigger in thrombocytopaenia (30), however the consensus is that a platelet count of $>50 \times 10^{9}$ should be achieved prior to invasive procedures (31) with a higher target of $>100 \times 10^{9}$ prior to neurosurgery.

Platelet function

Platelet function can be impaired by low $\mathrm{pH}$, hypothermia, myeloproliferative disease, uraemia, non-steroidal anti-inflammatory drugs and antiplatelet drugs. As well as having a sufficient number of platelets, adequate platelet function is also necessary for haemostasis. Platelet function is not measured in standard laboratory tests, but it is possible to measure platelet activity using methods such as aggregometry. Platelet function can be inferred from 


\begin{tabular}{|c|c|c|}
\hline Antiplatelet Drug Name & Mechanism of Action & $\begin{array}{c}\text { Implications for Cardiac } \\
\text { Surgery }\end{array}$ \\
\hline $\begin{array}{l}\text { Aspirin = Acetylsalicylic } \\
\text { acid }\end{array}$ & $\begin{array}{l}\text { Prevents Thromboxane A2 } \\
\text { production (by irreversibly } \\
\text { acetylating cyclooxygenase- } \\
\text { 1) therefore reducing } \\
\text { platelet aggregation }\end{array}$ & $\begin{array}{l}\text { Antithrombotic effect starts } \\
\text { within 30min of oral } \\
\text { loading dose and lasts for } \\
\text { lifespan of the platelet (8-10 } \\
\text { days). Is often continued } \\
\text { perioperatively with some } \\
\text { degree of platelet } \\
\text { dysfunction expected. }\end{array}$ \\
\hline $\begin{array}{l}\text { Thienopyridine } \\
\text { derivatives: } \\
\text { Clopidogrel, Ticlopidine, } \\
\text { Prasugrel }\end{array}$ & $\begin{array}{l}\text { Their metabolites covalently } \\
\text { bind to the P2Y12 receptor, } \\
\text { the main platelet receptor } \\
\text { responsible for ADP- } \\
\text { induced platelet } \\
\text { aggregation. }\end{array}$ & $\begin{array}{l}\text { Active within } 2 \mathrm{hrs} \text { of oral } \\
\text { loading dose. Lower risk of } \\
\text { GI-bleeding than aspirin. } \\
\text { Expect platelet dysfunction } \\
\text { if not discontinued at least } \\
7 \text { days pre-operatively (23). }\end{array}$ \\
\hline $\begin{array}{l}\text { Direct-acting P2Y12 } \\
\text { inhibitors: } \\
\text { Cangrelor, Ticagrelor, } \\
\text { Elinogrel }\end{array}$ & $\begin{array}{l}\text { These agents change P2Y12 } \\
\text { receptor conformation, } \\
\text { causing a reversible, } \\
\text { concentration-dependent } \\
\text { receptor inhibition. }\end{array}$ & $\begin{array}{l}\text { These are in phase } 3 \text { of } \\
\text { development }(24)\end{array}$ \\
\hline Dipyridamole & $\begin{array}{l}\text { Inhibits phosphodiesterase, } \\
\text { therefore increasing } \\
\text { intraplatelet concentrations } \\
\text { of cyclic AMP which } \\
\text { reduces the activation of } \\
\text { cytoplasmic second } \\
\text { messengers. Also stimulates } \\
\text { prostacyclin release and } \\
\text { inhibits thromboxane 2A } \\
\text { production }\end{array}$ & $\begin{array}{l}\text { Short half-life so usually } \\
\text { given as a slow-release } \\
\text { preparation. }\end{array}$ \\
\hline $\begin{array}{l}\text { Glycoprotein IIb/IIIa } \\
\text { receptor antagonists: } \\
\text { Abciximab, Tirofiban, } \\
\text { Eptifibatide }\end{array}$ & $\begin{array}{l}\text { Compete with ligand } \\
\text { binding of fibrinogen to } \\
\text { glycoprotein IIb/IIIa } \\
\text { receptor, therefore block the } \\
\text { final common pathway for } \\
\text { platelet aggregation. Given } \\
\text { intravenously as loading } \\
\text { bolus followed by infusion. }\end{array}$ & $\begin{array}{l}\text { Platelet function can take } 2 \\
\text { days to recover following } \\
\text { discontinuation of } \\
\text { Abciximab infusion. } \\
\text { Strategies to reduce blood } \\
\text { loss may include: } \\
\text { 1) Delaying surgery for } \\
\text { 12hrs post-abciximab, and } \\
\text { 2hrs post-tirofiban or } \\
\text { eptifibatide. } \\
\text { 2) Platelet transfusion (less } \\
\text { effective if given when free } \\
\text { drug still in circulation) } \\
\text { 3) Fibrinogen or } \\
\text { antifibrinolytics may be of } \\
\text { benefit }\end{array}$ \\
\hline
\end{tabular}

Fig. 6. Antiplatelet Agents, their mechanisms of action and implications for Cardiac Surgery 
thromboelastography (see later section). Bearing in mind the lack of routine platelet function measurement prior to cardiac surgery, it is important to identify clinical clues to impaired platelet activity. A patient's medication history should be noted. Some patients are advised to stop antiplatelet agents in advance of elective surgery. In those taking clopidogrel up to the day of surgery, platelet dysfunction should be anticipated as should the need for platelet transfusion.

\section{Prothrombin time (PT) and international normalized ratio (INR)}

Blood is sampled into a tube containing EDTA or citrate, both of which chelate calcium and prevent the blood clotting en route to the laboratory. The sample is centrifuged in the lab to yield platelet-poor plasma. The test starts when calcium and thromboplastin (consisting of tissue factor and phospholipid) are added to the plasma, and is complete when fibrin strands are formed. The time taken is the PT. The INR puts the measured PT in context by comparing it with the PT of a standardised plasma sample. An INR of 1.0 is normal; higher INRs represent coagulation that is impaired secondary to pathology or drugs. PT and INR are considered to be tests of the extrinsic pathway, with FVII deficiency having the greatest impact on raising the INR/PT. Other causes of abnormal PT and INR are shown in the table. Of note, the large amount of TF used to trigger coagulation in this test negates the effect of TFPI and renders the test independent of FVIII, FIX and FXI, meaning patients with haemophilia can have normal PT and INR results.

\section{Activated partial thromboplastin time (APTT) and aptt ratio (APTTR)}

The blood sample for this test is prepared in the same way as that for the PT. The resultant platelet-poor plasma is triggered to coagulate by mixing it with the APTT reagent and replacing the chelated calcium. The APTT reagent consists of phospholipid (as a substitute for the platelet membrane) and negatively-charged particles that cause contact activation. The time taken for fibrin strands to form is the APTT. The APTT ratio is calculated in a similar manner to the INR, with normal APTTR being 1.0 and higher values representing coagulopathy. APTT is prolonged by deficiencies of the Intrinsic or Common pathways, meaning any procoagulant factor deficiency apart from FVII and FXIII will prolong the

\begin{tabular}{|l|l|}
\hline \multicolumn{1}{|c|}{ Causes of Prolonged PT and INR } & \multicolumn{1}{c|}{ Notes } \\
\hline Decreased FVII & $\begin{array}{l}\text { FVII deficiency has a greater impact on PT and } \\
\text { INR than other factor deficiencies }\end{array}$ \\
\hline Decreased FI, FII, FV, FX & Decreased factor (including fibrinogen) synthesis \\
\hline Liver disease & $\begin{array}{l}\text { Synthesis of FII, FVII, FIX, FX are vitamin K- } \\
\text { dependent }\end{array}$ \\
\hline Vitamin K deficiency & Widespread factor depletion due to consumption \\
\hline $\begin{array}{l}\text { Disseminated Intravascular } \\
\text { Coagulation (DIC) }\end{array}$ & $\begin{array}{l}\text { Dilution artefact due to standard volume of } \\
\text { citrate (or EDTA) mixing with lower volume of } \\
\text { plasma }\end{array}$ \\
\hline High dose heparin & $\begin{array}{l}\text { Thus lower percentage volume of plasma, also } \\
\text { leads to dilution artefact }\end{array}$ \\
\hline Sample tube under-filled &
\end{tabular}

Fig. 7. Causes of Prolonged PT and INR 
APTT. APTT is used to titrate unfractionated heparin anticoagulation. It is also a screening tool for Haemophilia A and B. Prolonged APTT does not necessarily predict clinical bleeding, for example FXII deficiency greatly prolongs APTT but is not associated with bleeding tendency.

\begin{tabular}{|l|l|}
\hline Causes of Prolonged APTT and APTTR & Notes \\
\hline $\begin{array}{l}\text { Procoagulant factor deficiency (except } \\
\text { FVII or FXIII) }\end{array}$ & $\begin{array}{l}\text { FVII is not involved in the intrinsic pathway. } \\
\text { Completion of the test does not require } \\
\text { FXIII-dependent cross-linking of fibrin. }\end{array}$ \\
\hline Specific Clotting Factor Inhibitors & $\begin{array}{l}\text { eg. Factor VIII inhibitors develop in up to } \\
10 \% \text { of patients with haemophilia A }\end{array}$ \\
\hline Contamination of sample with heparin & $\begin{array}{l}\text { Sample drawn from vein upstream of } \\
\text { heparin infusion, or contaminated by } \\
\text { heparin in the pressure-bag of an arterial line }\end{array}$ \\
\hline Dilution artefact & $\begin{array}{l}\text { This is a non-specific inhibitor of the intrinsic } \\
\text { pathway so prolongs APTT. Paradoxically, } \\
\text { patients with lupus anticoagulant actually } \\
\text { have a prothrombotic tendency. }\end{array}$ \\
\hline $\begin{array}{l}\text { Underfilling of the sample tube, or raised } \\
\text { haematocrit will increase the proportion of } \\
\text { citrate (or EDTA) to plasma }\end{array}$ \\
\hline
\end{tabular}

Thrombin clotting time (TT or TCT) and hemoclot ${ }^{\circledR}$

TT measures the time taken for fibrin to form when thrombin is added to the plasma sample. Prolongation of TT suggests low fibrinogen levels, dysfibrinogenaemia or inhibition of thrombin. Thrombin can be inhibited by unfractionated heparin or direct thrombin inhibitors. Fibrin degradation products inhibit fibrin cross-linking; at high concentrations these can also prolong the TT.

Adding Protamine sulphate to the sample will negate the effect of heparin and FDPs. Adding Toluidine Blue will negate the effect of heparin but not FDPs. Another technique for samples containing heparin is to perform a "Reptilase Test", where a snake venon product 'Reptilase' is used to activate fibrinogen. Unlike thrombin, reptilase is not inhibited by heparin.

Hemoclot ${ }^{\circledR}$ is a sensitive, diluted TT assay.

These tests are used to assess the effectiveness of fibrinolytic therapy and may be useful in quantifying the effects of direct thrombin inhibitor drugs.

Ecarin clotting time (ECT)

This is a specific assay of thrombin generation. Ecarin comes from snake venom, and specifically activates prothrombin (FII). ECT can be used to monitor anticoagulation during Cardiopulmonary Bypass but is not widely utilised outside a research setting (13)

Fibrinogen

Fibrinogen (FI), the precursor of fibrin, is synthesised by hepatocytes and normal plasma concentration is $1.5-4.0 \mathrm{~g} / \mathrm{L}$. Levels vary seasonally within an individual, and causes of abnormal fibrinogen level or function are shown in the tables below. Fibrinogen can be depleted by haemorrhage and consumed by coagulation during or after cardiac surgery, 
and is routinely quantified by the Clauss method in this setting. The PT-derived fibrinogen level (PT-Fg) is more convenient but less reliable. When investigating congenital fibrinogen defects, more complex and time-consuming tests are employed.

There is evidence that the low preoperative fibrinogen concentrations correlate with higher peri-operative blood loss in coronary artery bypass surgery $(32,33)$. Pre-operative prophylactic fibrinogen infusion may be beneficial, although larger trials are required to determine safety and efficacy of this practice (34). Pre-operative hyperfibrinogenaemia is associated with higher all-cause mortality (35), possibly because raised fibrinogen levels are a marker of inflammation, reflecting the presence of a systemic disorder (eg sepsis, acute coronary syndrome).

In major blood loss treated with packed red blood cells and crystalloid/colloid intravascular volume resuscitation, fibrinogen is the first coagulation factor to become depleted (36). It is therefore a useful marker for severity of haemorrhage (37).

Fibrinogen quality is assessed when thromboelastometry is performed in the presence of a platelet inhibitor, a test available commercially as "FIBTEM" (see ROTEM section).

A prolonged Thrombin Time will also detect low fibrinogen levels.

Options for replacing fibrinogen are fibrinogen concentrate reconstituted to $20 \mathrm{~g} / \mathrm{L}$, Fresh Frozen Plasma containing 1.6-2g/L fibrinogen, or cryoprecipitate containing $17 \mathrm{~g} / \mathrm{L}$. The traditional target of replacement of fibrinogen aimed for a level of $1 \mathrm{~g} / \mathrm{L}$, but higher targets of $1.5-2 \mathrm{~g} / \mathrm{L}$ may be more appropriate in patients undergoing cardiac surgery (38).

It remains to be established whether it is better to administer fibrinogen concentrate prophylactically, or to reserve treatment only for patients who are bleeding. There is also debate regarding the most suitable goal for fibrinogen replacement, which may be fibrinogen quantity (eg Clauss assay) or fibrin quality (eg. FIBTEM).

\section{The Clauss assay}

A high concentration of thrombin is added to diluted plasma and the clotting time is measured. A reference curve has been plotted using plasma of known fibrinogen concentrations. The fibrinogen concentration of the test sample is determined by comparing the clotting time with the reference curve. The clotting time can be determined automatically using systems that detect changes in light scattering, or light absorption as fibrin is formed. Artefacts can occur when turbid or lipaemic plasma causes abnormal light scattering, and when free haemoglobin or bile cause abnormal light absorption. Heparin will affect clot formation, making the Clauss assay inaccurate, so every effort should be made to obtain a heparin-free sample (avoid sampling within 4 hours of low-molecular weight heparin administration, caution when sampling from arterial lines flushed with heparin). If a heparin-free sample cannot be obtained (eg during Cardiopulmonary Bypass) then ionexchange resins or heparinase can be used to negate the heparin effect. Fibrin Degradation Products (FDPs) affect fibrinogen activity in vivo, and also affect the time taken to complete the Clauss assay, so this assay naturally reflects the any potential impact of FDPs.

PT-derived fibrinogen assays (PT-Fg)

This method indirectly measures fibrinogen by analysing the change in light scattering or optical density as fibrin is formed in the sample during the PT test. The advantage of this method is that it can give a measurement of fibrinogen any time the PT is tested without additional expense. The test may be inaccurate in samples with high fibrinogen and, of particular relevance to Cardiac Surgery, the test may be less reliable than Clauss in the investigation of bleeding diathesis. FDPs have less effect on the PT-Fg than on the Clauss 


\begin{tabular}{|l|l|}
\hline $\begin{array}{c}\text { Causes of Elevated Plasma Fibrinogen } \\
\text { Concentration }\end{array}$ & Notes \\
\hline Increased age & \\
\hline Female Sex & \\
\hline Pregnancy and Oral Contraception & \\
\hline Acute phase reaction & \\
\hline Smoking & \\
\hline Acute exercise & Higher fibrinogen levels in winter \\
\hline Disseminated malignancy & $\begin{array}{l}\text { Occurs in 20\% of population, leads to 7-10\% } \\
\text { higher fibrinogen levels than GG genotype (39) }\end{array}$ \\
\hline Seasonal change & \\
\hline $\begin{array}{l}\text { Genetic Polymorphism of the beta } \\
\text { fibrinogen gene promoter (G-455A) }\end{array}$ & \\
\hline
\end{tabular}

\begin{tabular}{|l|l|}
\hline \multicolumn{1}{|c|}{$\begin{array}{c}\text { Causes of Decreased Plasma } \\
\text { Fibrinogen Concentration }\end{array}$} & \multicolumn{1}{c|}{ Notes } \\
\hline Inherited Fibrinogen Defects (rare): & $\begin{array}{l}\text { Grossly decreased fibrinogen synthesis, with low or } \\
\text { undetectable plasma fibrinogen. Patients have } \\
\text { haemorrhagic diathesis, prolonged clotting times } \\
\text { and abnormal platelet function }\end{array}$ \\
\hline Congenital Afibrinogenaemia & $\begin{array}{l}\text { Mild-to-moderate reduction in circulating fibrinogen } \\
\text { levels. Potential for haemorrhagic problems, but } \\
\text { patient may be asymptomatic. }\end{array}$ \\
\hline Congenital Dysfibrinogenaemia & $\begin{array}{l}\text { Immunoassays may detect fibrinogen, but tests that } \\
\text { depend on production of fibrin strands will give } \\
\text { lower fibrinogen results. Patients may have } \\
\text { haemorrhagic tendency, thrombophilia or be } \\
\text { asymptomatic }\end{array}$ \\
\hline Acquired hypofibrinogenaemia & $\begin{array}{l}\text { Hepatocellular failure leads to decreased fibrinogen } \\
\text { synthesis. Excessive glycosylation of fibrinogen leads } \\
\text { to an acquired dysfibrinogenaemia. Excess Fibrin } \\
\text { Degradation Products (FDPs) also disrupt fibrinogen } \\
\text { function. }\end{array}$ \\
\hline Decompensated liver disease & $\begin{array}{l}\text { Generalised fibrin formation throughout the } \\
\text { microcirculation leads to consumption and depletion } \\
\text { of fibrinogen. FDP concentration is also raised. }\end{array}$ \\
\hline Systemic Thrombolytic Therapy & $\begin{array}{l}\text { From massive blood transfusion or fluid } \\
\text { administration }\end{array}$ \\
\hline Viral Hepatitis \\
Coagulation (DIC)
\end{tabular}


assay; an adequate fibrinogen measurement using PT-Fg may not reflect adequate fibrinogen activity if there is a significant quantity of FDPs in circulation.

\section{Clottable protein}

This test is too time-consuming and labour-intensive to be used routinely, but does give very accurate results and can be used for reference assays.

\section{Testing for specific coagulation factor abnormalities}

Clinical or laboratory evidence of abnormal coagulation that is not explained by haemorrhage, known pathology, or iatrogenic causes may require investigation of specific factor abnormalities. Uncommonly, individuals may have a factor deficiency or a factor inhibitor (the most common example is lupus anticoagulant). Consultation with a haematologist followed by specialised laboratory tests may be indicated.

\section{Other measurements in coagulopathy}

For effective coagulation, supportive management to maintain homeostasis is required. Temperature $<34^{\circ} \mathrm{C}, \mathrm{pH}<7.1$, ionised Calcium $<0.9 \mathrm{mmol} / \mathrm{L}$ and Haematocrit $<30 \%$ have all been shown to adversely affect haemostasis (40).

In coagulopathy, hypocalcaemia should be corrected because of calcium's key role in the activation of FX, FII, FXIII and Fibrinogen. Both haemodilution and chelation of serum calcium by citrate in units of packed red blood cells can contribute to hypocalcaemia in massive transfusion. A value for ionised Calcium can be rapidly obtained from many blood gas analysis machines, and the reference range is $1.0-1.3 \mathrm{mmol} / \mathrm{L}$ (no correction calculation required). Total Calcium ranges from $2.1-2.7 \mathrm{mmol} / \mathrm{L}$ (corrected for hypoalbuminaemia may be necessary).

Prevention of heat loss and active warming may be required to raise core temperature, acidotic patients may benefit from buffering, and haematocrit should be maintained with transfusion to optimise coagulation.

When transfusing Packed Red Cells it is preferable to use blood that has been stored for the minimum possible duration, ideally less than two weeks. Transfusion of older blood has been associated with greater incidence of complications and higher mortality (41).

\section{Near patient coagulation tests}

ACT and TEG are the two most common Near Patient Tests (NPT) used in cardiac surgery. The main value of NPT is the short turn-around time, which gives feedback to the treating physician/surgeon without delay. An ACT reading can be obtained generally within 4 minutes of test initialisation, and a TEG within 10 to 15 minutes. A conventional coagulation screen generally has a turn-around time of 30 minutes, during which time one or more interventions may already have taken place, making the result less valuable and potentially obsolete.

\section{ACT (Activated Clotting Time)}

This is generally performed at the bedside or in the operating room by a perfusionist or doctor who is actively managing the patient. A pre-heparin baseline value is obtained to assist interpretation of subsequent results. Anticoagulation whilst on cardiopulmonary bypass $(\mathrm{CPB})$ is usually guided by $\mathrm{ACT}$, and the test is also used to assess success of protamine reversal of heparin when $\mathrm{CPB}$ is over. After Protamine, an ACT that is prolonged beyond the baseline value suggests heparin reversal may be incomplete, but it offers no information regarding other potential causes of coagulopathy. 


\section{Thromboelastography}

Thromboelastography was first described in 1948. Viscoelastic changes during coagulation are plotted against time(42). The abbreviation 'TEG' was used for this technique. TEG ${ }^{\circledR}$ is now a trademark for one manufacturer of thromboelastograph device, an alternative manufacturer uses the trademark ROTEM ${ }^{\circledR}$. The principles are similar, described below.

\section{The principles of the thromboelastography (TEG)}

Samples for analysis are stored in a citrated tube and must be analysed within 4 hours. Kaolin (a clotting factor) is added to two separate cuvettes both containing sufficient calcium chloride to reverse the effect of the citrate. One of the cuvettes also contains a surface coating of heparinase to deactivate any heparin in the sample. Both cuvettes are loaded onto the analyser for simultaneous analysis.

Each cuvette sits on a platform that oscillates through an angle of $4045^{\prime}$. The whole cycle lasts ten seconds including a 1 second rest period. A pin is freely suspended within the blood and is attached to a torsion wire which in turn is attached to a mechanical-electrical transducer. As the blood starts to clot within the cuvette, fibrin strands form between the blood and the pin and the torque is transmitted via the transducer to give a signal that is recorded by a computer (See figure 8 ).

The variables that are recorded are as follows: " $r$ " (reaction time) is the period of time, in minutes, taken to form the initial fibrin strands after placement of blood in the TEG analyser.

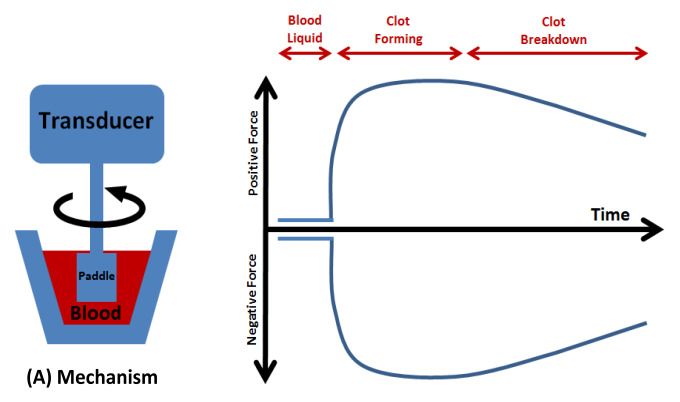

(B) Construction of the Curve

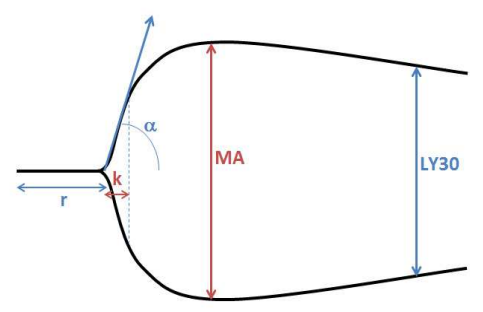

(C) Thromboelastogram Parameters

Fig. 8. This image represents the TEG diagrammatically. (A) Shows a cross-sectional view of the apparatus. (B) Demonstrates the construction of the curve. (C) Shows the final printout of the TEG 
Before this happens, the liquid blood in the cuvette exerts very little torque on the pin and the signal remains effectively zero (see figure 8 ). It is prolonged by congenital or acquired deficiencies in hepatic coagulation factors and anticoagulants such as unfractionated heparin, the low molecular weight heparins and warfarin. The " $\mathrm{K}$ " ( $\mathrm{K}$ time) is the time, in minutes, after clot formation begins and the clot itself is of sufficient strength to produce a $20 \mathrm{~mm}$ divergence of the line. This reflects the speed of clot strengthening. The " $K$ " is reduced by an elevated fibrinogen and by effective platelet function and is prolonged by the same factors that prolong the " $r$ ". The " $a$ " (alpha angle), measured in degrees, is the slope of the TEG tracing with respect to the $r$ line (the line drawn between $r_{1}$ and $r_{2}$ ). It reflects the speed at which the clot is formed and behaves very much like the " $K$ ". If the " $K$ " is undefined (i.e. the signal generated by the computer never reaches an amplitude of $20 \mathrm{~mm}$ ) such as in hypocoaguable states then the " $\alpha$ " becomes more important. The "MA" (maximum amplitude) is a measure of the maximum strength developed by the clot. It is dependent on fibrin formation and platelet function. Percentage clot lysis is estimated at 30 (LY30) minutes or 60 (LY60) minutes after the "MA" is reached. The percentages are calculated by using the following formula: $\mathrm{LY} 30=\left(\mathrm{MA}-\mathrm{A}_{30}\right) / \mathrm{MA} \times 100$ and $\mathrm{LY} 60=\left(\mathrm{MA}-\mathrm{A}_{60}\right) / \mathrm{MA} \times 100$, where $\mathrm{A}_{30}$ is the amplitude of the trace 30 minutes after "MA" is reached and $\mathrm{A}_{60}$ the corresponding value after 60 minutes. If the LY30 or LY60 are high then fibrinolysis is high. Finally, "C.I." (coagulation index) can also be derived from " $\mathrm{r}$ ", " $\mathrm{K}$ ", " $\mathrm{a}$ " and "MA" by substitution into the following equation: C.I. $=0.3258 \mathrm{r}-0.1886 \mathrm{~K}+0.1224 \mathrm{MA}+0.0759 \mathrm{a}-7.7922$. This equation has been derived after multiple regression of a large database of TEG tracings. The "C.I." reflects the patient's overall coagulation state and normal values range from - 3.0 to +3.0 (43).

Platelet mapping with TEG

Platelet mapping studies measure the degree to which a patient's platelets can be activated by stimulation of either the thromboxane A2 (Txa2) receptor or the adenosine diphosphate (ADP) receptor. These receptors can be inhibited by aspirin and clopidogrel respectively, but the degree of inhibition varies between individuals. Thrombin activates platelets independent of the arachidonic acid and ADP receptors via the glycoprotein IIb/IIIa receptor.

In cardiac surgery, antiplatelet agents are often withheld to minimise bleeding complications, which can expose patients to increased risks of peri-operative myocardial ischaemia. Platelet mapping may have a role in determining the optimum time to operate, such that antiplatelet agents are withheld for long enough to decrease the bleeding risk, but no longer than necessary. In the medical management of coronary artery disease, this technique could potentially be used before antiplatelet therapy is commenced, to determine which antiplatelet agent is likely to be effective for an individual patient. It might also be used after antiplatelet therapy has been initiated to measure the response to therapy.

Platelet mapping can be assessed by the following method: 4 TEG channels (cups) are required. Cup 1 contains blood and kaolin (this activates the clotting cascade ex vivo) and the MA reflects thrombin activated platelets $\left(\mathrm{MA}_{\text {thrombin }}\right)$. Thrombin in the blood sample is produced by trauma during the blood sampling procedure. Since the direct effect of thrombin on the IIb/IIIa receptor is not dependent on stimulation of either the Txa2 or ADP receptors, $\mathrm{MA}_{\text {thrombin }}$ is an indirect measure of platelet function even in the presence of aspirin or clopidogrel. In all other 3 cups heparin is added to inhibit thrombin thus eliminating its direct action on the $\mathrm{IIb} / \mathrm{III}$ a receptor. To the second cup $10 \mu \mathrm{L}$ reptilase and activated factor XIII (Activator F) is added which convert fibrinogen to fibrin by generating a cross-linked fibrin clot thus isolating the contribution of fibrin to the clot strength. 
Activator F has no effect on platelets so the "MA" reflects the action of fibrin only $\left(\mathrm{MA}_{\text {fibrin }}\right)$ (44). To the third cup $10 \mu \mathrm{L}$ Activator F and $10 \mu \mathrm{L}$ arachidonic acid (AA) are added and the $\mathrm{MA}_{\mathrm{AA}}$ reflects platelet responsiveness to AA. To the fourth cup $10 \mu \mathrm{L}$ Activator $\mathrm{F}$ and $10 \mu \mathrm{L}$ $\mathrm{ADP}$ are added and the $\mathrm{MA}_{\mathrm{ADP}}$ reflects platelet responsiveness to ADP. The relative response of platelets to either AA or ADP is calculated as follows with a normal reference value for each being above $80 \%$ :

$$
\begin{aligned}
& \text { Relative response of platelets to } \mathrm{AA}=\left(\mathrm{MA}_{\mathrm{AA}}-\mathrm{MA}_{\text {fibrin }}\right) /\left(\mathrm{MA}_{\text {thrombin }}-\mathrm{MA}_{\text {fibrin }}\right) \times 100 \text {. } \\
& \text { Relative response of platelets to } \mathrm{ADP}=\left(\mathrm{MA}_{\mathrm{ADP}}-\mathrm{MA}_{\text {fibrin }}\right) /\left(\mathrm{MA}_{\text {thrombin }}-\mathrm{MA}_{\text {fibrin }}\right) \times 100 \text {. }
\end{aligned}
$$

The platelet inhibition in response to an agonist is calculated by subtracting the percentage aggregation from 100 (45).

\section{Rotational Thromboelastometry (ROTEM $\left.{ }^{\circledR}\right)$}

ROTEM is based on the same principles as thromboelastography. Citrated whole blood is mixed with reagents in a stationary cuvette, then a pin is placed vertically into the blood and alternating clockwise and anticlockwise forces are applied to the pin. As the blood clots the pin's oscillation is impeded, and when fibrinolysis occurs the pin will move more freely.

The device records the changes in oscillation against time, creating the 'thromboelastogram' (TEM). The zero line indicates free movement of the pin. An amplitude of $100 \mathrm{~mm}$ would indicate no movement of the pin, meaning the clot has reached the maximum possible firmness measurable by ROTEM. Combinations of reagents can be used to produce a series of TEMs that measure different aspects of the coagulation and fibrinolysis processes.

The ROTEM machine has four channels, thus four TEMs can be generated simultaneously. By using combinations of coagulation triggers and coagulation inhibitors, a clearer understanding of the coagulation abnormalities can be obtained. The reference ranges for the parameters are not interchangeable between the different types of TEM, for example the MCF seen in the FIBTEM test will be significantly lower than that in INTEM or EXTEM, because clot firmness is due to the effect of fibrin only.

\begin{tabular}{|c|c|c|}
\hline $\begin{array}{l}\text { ROTEM Parameter } \\
\text { [Measured Variable] }\end{array}$ & Significance & Clinical Application \\
\hline $\begin{array}{l}\text { Clotting time (CT) } \\
\text { [Delay from the start of the } \\
\text { reaction to the start of clot } \\
\text { formation. } \\
\text { An amplitude of } 2 \mathrm{~mm} \text { is } \\
\text { taken to signify the start of } \\
\text { clot formation.] }\end{array}$ & $\begin{array}{l}\text { This represents: } \\
\text { - the initiation of clotting } \\
\text { - thrombin formation } \\
\text { - the start of clot polymerisation } \\
\text { Although not linearly related, CT is } \\
\text { related to the PT for EXTEM, and } \\
\text { the APTT for INTEM. } \\
\text { Abnormalities that prolong the } \\
\text { laboratory tests will prolong the CT } \\
\text { in the comparable ROTEM test, but } \\
\text { the endpoint for the laboratory test } \\
\text { is fibrin formation, whereas in } \\
\text { ROTEM a degree of fibrin } \\
\text { stabilisation is required to attain } \\
\text { 2mm amplitude. }\end{array}$ & $\begin{array}{l}\text { Prolonged CT suggests } \\
\text { anticoagulant drug activity or } \\
\text { coagulation factor } \\
\text { abnormalities. } \\
\text { Consider: } \\
\text { - Anticoagulant inhibitors such } \\
\text { as protamine. } \\
\text { - Replacement of coagulation } \\
\text { factors (eg. specific factor } \\
\text { loncentrates, or fresh frozen } \\
\text { plasma) }\end{array}$ \\
\hline
\end{tabular}

Parameters measured using the ROTEM are as follows: 


\begin{tabular}{|c|c|c|}
\hline $\begin{array}{l}\text { ROTEM Parameter } \\
\text { [Measured Variable] }\end{array}$ & Significance & Clinical Application \\
\hline \begin{tabular}{|l} 
Clot Formation Time \\
(CFT) \\
[Delay from start of the \\
reaction $(2 \mathrm{~mm})$ to \\
formation of a $20 \mathrm{~mm}$ clot. $]$
\end{tabular} & $\begin{array}{l}\text { CFT represents fibrin } \\
\text { polymerisation, and stabilisation of } \\
\text { the clot by activated platelets and } \\
\text { FXIII. } \\
\text { Prolonged CFT signifies a } \\
\text { hypocoagulable state, and a short } \\
\text { CFT corresponds with a } \\
\text { hypercoagulable state. }\end{array}$ & $\begin{array}{l}\text { Prolonged CFT may represent: } \\
\text { - deficiency of platelet quantity } \\
\text { or function } \\
\text { - low fibrinogen level } \\
\text { - deficiency of fibrin } \\
\text { polymerisation } \\
\text { Consider: } \\
\text { - fibrinogen replacement } \\
\text { (fibrinogen concentrate, } \\
\text { cryoprecipitate, fresh frozen } \\
\text { plasma) } \\
\text { - platelet transfusion }\end{array}$ \\
\hline $\begin{array}{l}\text { Alpha(a)-angle } \\
\text { [Angle formed between } \\
\text { the } x \text { axis and a line that } \\
\text { forms a tangent with the } \\
\text { temogram curve and } \\
\text { crosses the } x \text { axis at the } \\
\text { point where clotting starts } \\
(2 \mathrm{~mm}) \text { ] }\end{array}$ & $\begin{array}{l}\text { This describes the kinetics of } \\
\text { clotting. } \\
\text { A reduced } \alpha \text {-angle will correspond } \\
\text { with a prolonged CFT. Increased } \alpha \text { - } \\
\text { angle will be seen in a } \\
\text { hypercoagulable state. }\end{array}$ & $\begin{array}{l}\text { Reduced angle indicates a } \\
\text { hypocoagulable state, consider } \\
\text { the same causes and } \\
\text { management as described for } \\
\text { CFT. }\end{array}$ \\
\hline $\begin{array}{l}\text { A }(\mathbf{x}) \text { values } \\
\text { [This is the amplitude at } \\
\text { time } x \text { after the clot has } \\
\text { started to form. (eg the } \\
\text { A10 value is the amplitude } \\
\text { at } 10 \text { minutes after CT)] }\end{array}$ & $\begin{array}{l}\text { Low values are caused by the same } \\
\text { abnormalities that prolong CFT and } \\
\text { decrease the } \alpha \text {-angle (platelets, } \\
\text { fibrinogen, FXIII) }\end{array}$ & $\begin{array}{l}\text { Reduced A }(\mathrm{x}) \text { Values indicate a } \\
\text { hypocoagulable state, consider } \\
\text { the same causes and } \\
\text { management as described for } \\
\text { CFT. }\end{array}$ \\
\hline $\begin{array}{l}\text { Maximum Clot Firmness } \\
\text { (MCF) } \\
\text { [The peak amplitude of the } \\
\text { Temogram] }\end{array}$ & $\begin{array}{l}\text { Low MCF indicates a soft clot with } \\
\text { potential for haemorrhage. } \\
\text { Inadequate clot quality can reflect } \\
\text { an abnormality of platelets, } \\
\text { fibrinogen or FXIII. } \\
\text { It can also be caused by } \\
\text { hyperfibrinolysis. } \\
\text { High MCF suggests a } \\
\text { hypercoagulable state. }\end{array}$ & $\begin{array}{l}\text { With low MCF: } \\
\text { - exclude hyperfibrinolysis } \\
\text { - consider supplementing } \\
\text { fibrinogen and/or platelets }\end{array}$ \\
\hline $\begin{array}{l}\text { Lysis Index at } 30 \text { minutes } \\
\text { (LI30) } \\
\text { [The amplitude } 30 \text { minutes } \\
\text { after CT, given as a } \\
\text { percentage of MCF (the \% } \\
\text { remaining clot firmness) } \\
\text { (LI45 and LI60 can be used } \\
\text { to quantify late } \\
\text { fibrinolysis)] }\end{array}$ & $\begin{array}{l}\text { In health, the high concentration of } \\
\text { fibrinolysis inhibitors means there } \\
\text { is negligible fibrinolysis and LI30 } \\
\text { should be close to } 100 \%\end{array}$ & $\begin{array}{l}\text { An abnormally low LI30 usually } \\
\text { indicates hyperfibrinolysis, so } \\
\text { antifibrinolytic drugs should be } \\
\text { considered. }\end{array}$ \\
\hline
\end{tabular}




\begin{tabular}{|l|l|l|}
\hline \multicolumn{1}{|c|}{$\begin{array}{c}\text { ROTEM Parameter } \\
\text { [Measured Variable] }\end{array}$} & \multicolumn{1}{c|}{ Significance } & \multicolumn{1}{c|}{ Clinical Application } \\
\hline Maximum Lysis (ML) & $\begin{array}{l}\text { This value represents the inverse of } \\
\text { LI (\% remaining clot firmness + \% } \\
\text { clot firmness lost = 100\%) } \\
\text { This value will increase if an } \\
\text { extended measurement period is } \\
\text { used. }\end{array}$ & $\begin{array}{l}\text { An abnormally high ML usually } \\
\text { indicates hyperfibrinolysis, so } \\
\text { antifibrinolytic drugs should be } \\
\text { amplitude (relative to the } \\
\text { peak at MCF) that has } \\
\text { occurred by the end of the } \\
\text { measurement period given } \\
\text { as a percentage of MCF. } \\
\begin{array}{l}\text { This is the \% clot firmness } \\
\text { lost.] }\end{array}\end{array}$ \\
\hline
\end{tabular}

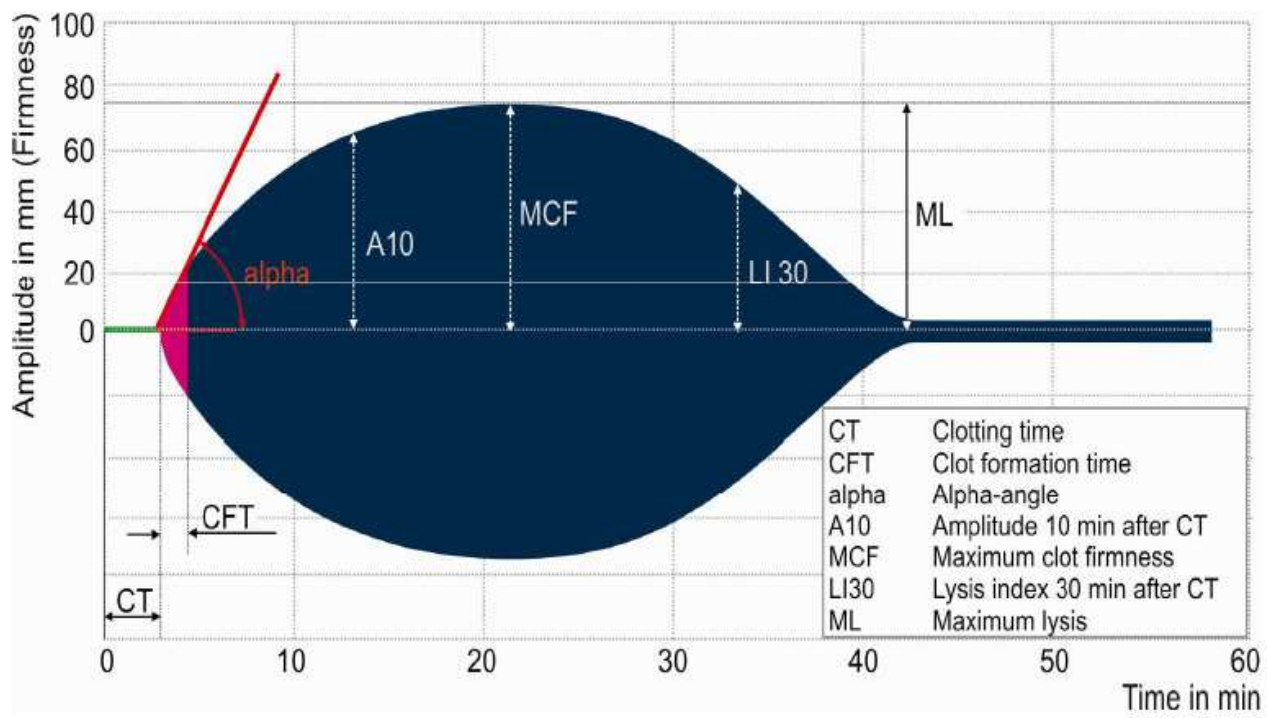

[Reproduced with permission of Tem International $\mathrm{GmbH}$ ]

Fig. 9. ROTEM graph and basic parameters (a graph of an unstable clot has been chosen to enable illustration of the lysis parameters)

The available ROTEM tests are described below:

\begin{tabular}{|c|c|}
\hline $\begin{array}{l}\text { Name of Test } \\
\text { [Test description] }\end{array}$ & $\begin{array}{c}\text { Relevant Parameters } \\
\text { [Considerations if parameters are abnormal ] }\end{array}$ \\
\hline $\begin{array}{l}\text { INTEM } \\
\text { [Mild intrinsic coagulation } \\
\text { pathway activation] }\end{array}$ & $\begin{array}{l}\text { CT [Factor deficiency (intrinsic pathway); Anticoagulant } \\
\text { effects (heparin, thrombin inhibitors)] } \\
\text { MCF, A(x), CFT, } \alpha \text {-angle [Platelet contribution to clot } \\
\text { firmness; Fibrinogen concentration; Fibrin } \\
\text { polymerisation] } \\
\text { ML, LI(x) [Hyperfibrinolysis] }\end{array}$ \\
\hline
\end{tabular}




\begin{tabular}{|l|l|}
\hline \multicolumn{1}{|c|}{ [Test description] } & \multicolumn{1}{c|}{ [Considerations if parameters are abnormal ] } \\
\hline $\begin{array}{l}\text { HEPTEM } \\
\text { [Mild intrinsic pathway } \\
\text { activation. Heparinase added to } \\
\text { degrade any heparin present in } \\
\text { the sample.] }\end{array}$ & $\begin{array}{l}\text { If abnormal values seen on INTEM are corrected in the } \\
\text { HEPTEM graph, these effects are attributable to heparin. }\end{array}$ \\
\hline $\begin{array}{l}\text { EXTEM } \\
\text { [Mild extrinsic pathway } \\
\text { activation] }\end{array}$ & $\begin{array}{l}\text { CT [Factor deficiency (extrinsic pathway)] } \\
\mathbf{M C F}, \mathbf{A}(\mathbf{x}), \mathbf{C F T}, \mathbf{\alpha} \text {-angle [Platelet contribution to clot } \\
\text { firmness; Fibrinogen concentration; Fibrin } \\
\text { polymerisation] } \\
\mathbf{M L}, \mathbf{L I}(\mathbf{x}) \text { [Hyperfibrinolysis] } \\
\mathbf{M C F}, \mathbf{A}(\mathbf{x}), \mathbf{M L}, \mathbf{L I}(\mathbf{x}) \text { [FXIII deficiency] }\end{array}$ \\
\hline $\begin{array}{l}\text { FIBTEM } \\
\text { [Mild extrinsic pathway } \\
\text { activation. Platelet inhibitor } \\
\text { (cytochalasin D) added, } \\
\text { therefore the TEM represents } \\
\text { only the fibrin component of the } \\
\text { clot.] }\end{array}$ & $\begin{array}{l}\text { MCF, A(x), CFT, } \boldsymbol{\alpha} \text {-angle [Fibrinogen concentration and } \\
\text { Fibrin polymerisation] } \\
\mathbf{M L}, \mathbf{L I}(\mathbf{x}) \text { [Hyperfibrinolysis] } \\
\mathbf{M C F}, \mathbf{A}(\mathbf{x}), \mathbf{M L}, \mathbf{L I}(\mathbf{x}) \text { [FXIII deficiency] } \\
\text { When compared with EXTEM, FIBTEM gives an indirect } \\
\text { evaluation of the platelet contribution to clot }\end{array}$ \\
\hline $\begin{array}{l}\text { APTEM } \\
\text { [Mild extrinsic pathway } \\
\text { activator. Fibrinolysis inhibitor } \\
\text { (aprotinin) ] }\end{array}$ & $\begin{array}{l}\text { If abnormalities of EXTEM are corrected on APTEM they } \\
\text { are attributable to hyperfibrinolysis and may be } \\
\text { correctable with antifibrinolytic drugs. }\end{array}$ \\
\hline
\end{tabular}

A suitable combination of TEMs for a patient undergoing cardiac surgery would be INTEM, FIBTEM and HEPTEM. The INTEM is performed to look at CT (prolonged in consumptive coagulopathy and the heparin effect on the intrinsic pathway) and also the a-angle and MCF (to assess whether fibrinogen or platelet supplementation is needed). The HEPTEM is compared with INTEM to determine the degree of Heparin effect. FIBTEM is performed to define the fibrinogen contribution to the haemostatic plug.

As recommended at the European ROTEM meeting 2007, a minimum of 3 sets of ROTEM should be performed; a baseline, a set whilst on $\mathrm{CPB}$, and one after $\mathrm{CPB}$. Further sets are to be performed if the patient is still bleeding. These tests can be performed quickly and interpreted safely between 10-15 minutes from the start of the tests.

The FIBTEM test is used clinically to guide administration of fibrinogen (46), but evidence for the treatment trigger or therapeutic target has not been conclusively established. It has been suggested that a FIBTEM MCF of $7 \mathrm{~mm}$ is adequate for haemostasis in orthopaedic surgery, but a higher target of $22 \mathrm{~mm}$ has been discussed for cardiac surgery.

Caveats for ROTEM use:

The INTEM and EXTEM are not very sensitive to mild coagulation factor deficiencies, and are insensitive to defects of primary haemostasis (platelet aggregation). The EXTEM test may still be normal when INR is as high as 4 , and may show pathological values with very high heparin levels. 
Thromboelastography (TEG) versus Rotational Thromboelastometry (ROTEM)

As discussed above, the techniques have a common origin. Both systems generate graphs of clot firmness between a cuvette and pin versus time. In the TEG system the cuvette oscillates around a pin throughout the clotting process, whilst in the ROTEM system the cuvette is fixed and the pin rotates.

By convention, the parameters obtained from the graphs have been given different names in the two tests. A comparison of the nomenclature is given in the table below from an article by Luddington (42).

\begin{tabular}{lll}
\hline Instrumentation & TEG $^{\circledast}$ & ROTEM $^{\circledast}$ \\
\hline Measurement period & - & RT \\
Clot time (period to $2 \mathrm{~mm}$ amplitude) & $r$ & CT \\
Period from 2 to $20 \mathrm{~mm}$ amplitude & $k$ & CFT \\
Alpha angle & $\alpha$ (slope between & $\alpha$ (angle of tangent \\
& $r$ and $k$ ) & at 2 mm amplitude) \\
Maximum angle & - & CFR \\
Maximum strength & MA & MCF \\
Time to maximum strength & TMA & MCF-t \\
Amplitude (at set time) & A (A30, A60) & (A5, A10...) \\
Clot elasticity & G & MCE \\
Maximum lysis & - & ML \\
Lysis at a fixed time & CL30, CL60 & LY30, LY45, LY60 \\
Time to lysis & TTL (2 mm drop & CLT (10\% from MCF) \\
& from MA) & \\
Maximum lysis & - & CLR (maximum tangent \\
& & post-MCF)
\end{tabular}

Copyright of Clinical \& Laboratory Haematology is the property of Blackwell Publishing Limited and its contents may not be copied or emailed to multiple sites or posted to a listserv without the copyright holder's express written permission. However, users may print, download, or email articles for individual use.

Fig. 10. Nomenclature of TEG and ROTEM

Clinical application of near patient test results and evidence base for decision-making

There are several studies in the literature that highlight the usefulness of the TEG in cardiac surgery. Shore-Lesserson et al demonstrated in a prospective randomized controlled trial of high risk cardiac surgical patients $(n=105)$ that fewer patients randomized to the TEG arm were transfused fresh frozen plasma $(p<0.002)$ or platelets $(p<0.05)$ compared to those patients managed by standard coagulation tests in the postoperative period (47). Total blood product transfusion was less in the TEG arm and this reached statistical significance. TEG was used to guide protamine, platelet, FFP and antifibrinolytic therapy. The authors concluded that TEG -based transfusion algorithm reduced transfusion requirements.

Spiess et al assessed the usefulness of TEG in predicting postoperative haemorrhage and need for reoperation. They found that TEG was a better predictor (87\% accuracy) than coagulation profile (51\%) or activated clotting time (30\%) (48). Another study by the same author concluded that costs and risks associated with allogenic blood transfusions could be reduced with the introduction of a TEG based haemostasis protocol in cardiac surgery (49). Tuman found that TEG predicted postoperative haemorrhage more accurately than routine coagulation tests ( $88 \%$ versus $33 \%$ respectively) (50). 
Avidan et al (51) showed in a prospective randomised comparison trial that following algorithms based on point of care tests or on structured clinical practice with standard laboratory tests did not decrease blood loss, but did reduce the transfusion of all blood components $(p<0.05)$ after routine cardiac surgery, when compared with clinician discretion.

Finally, Westbrook et al showed in a prospective randomised controlled study a nonstatistically significant trend toward less blood product usage in a strict protocol utilizing TEG compared to physician's choice based on clinical experience and standard laboratory coagulation tests. The study also demonstrated a cost saving benefit (52).

Use of an automated protamine titration system, such as the commercially available pointof-care Hepcon ${ }^{\circledR}$, has been shown to be associated with higher heparin and lower protamine doses. This can potentially decrease activation of the coagulation and inflammatory cascades, with possible advantages of decreased postoperative bleeding and blood product requirement.(23)

Blood product administration in cardiac surgery and the cardiothoracic ICU

If a patient bleeds in the postoperative period, it is important to distinguish between 'surgical' and 'medical' bleeding. A 'medical bleed' from the microvasculature occurs due to a coagulation abnormality, and this abnormality must be detected and corrected with blood products or pharmacological agents to halt the bleeding. In contrast a 'surgical bleed' is from a cardiac or large vessel injury and will often require resternotomy to re-establish haemostasis surgically. Misdiagnosis of 'surgical bleeding' can lead to unnecessary resternotomy, whilst failure to diagnose a 'surgical bleed' may lead to delay and futile use of blood products. A progressive, untreated 'surgical bleed' will lead to a combined 'medical' AND 'surgical' bleed. Likewise, a 'medical bleed' that is not correctly treated may result in a pericardial tamponade that needs surgical intervention.

Factors to be considered in post-operative haemorrhage include:

- Complexity of surgery and adequacy of surgical haemostasis at end of operation

- Baseline coagulation status (APTT, PT, platelet count, ACT or TEG) compared with post-operative measurements

- Anticoagulation therapy pre-operatively (Antiplatelet therapy, Warfarin, Heparins, FXa or thrombin inhibitors)

- Intraoperative blood loss and blood product replacement

- CPB duration

- Intra-operative anticoagulant use and reversal

- Pump blood usage (this contains additional heparin, thus may require further protamine reversal).

- $\quad$ Core temperature

- $\quad$ Blood pH

- $\quad$ Ionised calcium level

Where possible, administration of blood products should be minimised(53). With donor screening and testing of donated blood, the risk of blood-borne disease transmission has decreased. Uncertainties regarding prion-related disease transmission remain, and there is also evidence that blood transfusion during cardiac procedures is associated with worse short- and long-term outcomes $(41,54)$. The measures below are adapted from the 2011 Blood Conservation Clinical Guidelines published by the Society of Thoracic Surgeons and the Society of Cardiovascular Anaesthesiologists.(55) 


\section{General Measures for Blood Conservation}

- If allogenic transfusion required, use leukodepleted red blood cells.

- Routine blood salvage with centrifugation is useful. Intra-op autotransfusion, either direct or following centrifugation is useful

- Blood salvage may be considered in malignancy, as the risk may be less than that associated with allogenic blood transfusion.

- Multidisciplinary blood management teams can limit transfusion and peri-operative bleeding whilst maintaining safe outcomes.

- Minimise volume taken for blood sampling

- Do not transfuse if $\mathrm{Hb} \geq 10 \mathrm{~g} / \mathrm{dL}$ unless specifically indicated

- Non-red cell haemostatic products ideally guided by point-of-care tests

- DDAVP (Desmopressin) considered if platelet dysfunction likely to respond (eg uraemia, type I von Willebrand's Disease)

- Consider FIX in Haemophilia B

Pre-op Measures

- Identify high risk patients and utilise all available measures to conserve blood in this setting (ie. increased age, pre-op anaemia, small body size, non-CABG or urgent surgery, pre-op antithrombotic drugs, acquired/congenital clotting abnormality, multiple comorbidities, thrombocytopenia or abnormal platelet function)

- Erythropoietin (EPO) and iron to correct anaemia, or for patients at high risk of developing anaemia

- If possible, stop platelet P2Y12 inhibitors [thienopyridine pro-drugs (ticlopidine, clopidogrel, prasugrel), direct-acting P2Y12 inhibitors (cangrelor, ticagrelor)] and delay surgery until effect has subsided

- Point-of-care testing of ADP-responsiveness may identify clopidogrel-nonresponders who do not require delay

\section{Intra-op Measures}

\section{Medical}

- Lysine analogues (E-aminocaproic acid, tranexamic acid) reduce blood loss.

- Risk/benefit ratio does not favour aprotinin use in adults

\section{Perfusion}

- $\quad$ Post-CPB pump salvage with reinfusion of pump blood is reasonable. Centrifugation is reasonable. Modified ultrafiltration is indicated.

- Mini-CPB-circuits, vacuum-assisted venous drainage and retrograde autologous $\mathrm{CPB}$ circuit priming may reduce transfusion requirements.

- Microplegia may reduce haemodilution associated with larger volumes of crystalloid cardioplegia solution

- $\quad$ During $\mathrm{CPB}$ with moderate hypothermia, $\mathrm{Hb} \geq 6 \mathrm{~g} / \mathrm{dL}$ may be adequate, but higher transfusion trigger may be appropriate for patients at greater risk of critical noncardiac end-organ ischaemia

- Open venous reservoir membrane oxygenator systems during CPB may decrease blood loss and improve safety

- If $\mathrm{CPB} \geq 2 \mathrm{hrs}$, higher and/or patient-specific heparin concentrations may reduce consumption of platelets and coagulation factors

- $\quad$ Protamine titration or empiric low-dose regimen post-CPB may decrease blood loss 


\section{Blood Products}

- Use safer fractionated products if possible, but plasma transfusion reasonable if multiple factor deficiencies and serious bleeding

- Prothrombin Concentrate Complex (PCC) preferable to plasma for warfarin reversal provided PCC contains adequate FVII

- Plasma transfusion considered as part of massive transfusion algorithm.

- Intra-op platelet plasmapheresis for platelet salvage considered in high risk patients

- Antithrombin III (AT) concentrate considered in patients with AT-mediated heparin resistance pre-CPB

\section{Surgical}

- $\quad$ TEVAR (thoracic endovascular aortic repair) may reduce blood loss compared with open procedure

- $\quad$ Off-pump CABG may reduce blood loss compared with CPB approach

- Topical haemostatic devices to aid anastomotic closure and topical antifibrinolytic agents may decrease blood loss.

\section{Post-op Measures}

- Routine dual antiplatelet therapy not indicated - only for patients with acute coronary syndrome or recent drug-eluting coronary artery stents

- Consider FXIII for clot stabilisation if bleeding persists despite routine blood conservation measures

- Consider FVIIa for intractable non-surgical bleeding unresponsive to routine haemostatic management

- Mediastinal shed blood reinfusion, following washing and centrifugation, can be considered (direct reinfusion not recommended)

- $\quad$ Therapeutic PEEP trial to decrease post-op bleeding is not well established

Choice of fluid for intravascular volume replacement can also affect coagulation. Colloidal plasma substitutes may interfere with haemostasis in non-specific or specific ways. Nonspecific effects relate to haemodilution, with decreased circulating concentrations of coagulation factors, platelets and red blood cells. Specific effects are discussed by colloid type.

Albumin inhibits platelet aggregation directly (56), and may affect fibrin polymerisation, but in vitro is considered not to affect haemostasis (57).

Dextrans are not widely used due to potential allergic, renal and haemostatic side effects. They cause platelet dysfunction by decreasing vWF, possibly by adsorption. Dextrans also accelerate activation of fibrinogen, facilitate fibrinolysis, and may coat endothelium and platelets thus decreasing platelet adhesion.

Gelatins can impair platelet coagulation (58) and decrease vWF, but are generally accepted not to influence perioperative bleeding (57).

Hydroxyethyl starches (HES) induce platelet dysfunction through effects on GPIIb-IIIa expression and on vWF and FVIII levels. HES can also favour fibrinolysis. Haemorrhagic complications have been reported more frequently with high molecular weight (Mw) HES than with lower Mw.

Use of colloids outside the context of clinical studies has recently been questioned as well (59). When using crystalloid alternatives, a balanced salt solution may offer less disruption of haemostasis than saline, possibly due to maintenance of plasma calcium concentrations. 


\section{Conclusion}

Perioperative management of coagulation needs to be tailored to the needs of the individual patient and delivered within the available resources of the Cardiac Surgery Centre. Appropriate use of medication and blood products can minimise perioperative thrombosis and bleeding, limit exposure to potentially harmful blood products and thus maximise quality of patient care.

\section{Acknowledgement}

Supported by St. Vincent's Anaesthesia Foundation.

\section{References}

[1] Shander A, Moskowitz D, Rijhwani TS. The safety and efficacy of "bloodless" cardiac surgery. Semin Cardiothorac Vasc Anesth. 2005;9(1):53-63. Epub 2005/03/01.

[2] Boldt J, Haisch G, Kumle B, Brosch C, Lehmann A, Werling C. Does coagulation differ between elderly and younger patients undergoing cardiac surgery? Intensive Care Med. 2002;28(4):466-71. Epub 2002/04/23.

[3] Prisco D, Paniccia R. Point-of-Care Testing of Hemostasis in Cardiac Surgery. Thromb J. 2003;1(1):1. Epub 2003/08/09.

[4] Spiess BD, Royston D, Levy JH, Fitch J, Dietrich W, Body S, et al. Platelet transfusions during coronary artery bypass graft surgery are associated with serious adverse outcomes. Transfusion. 2004;44(8):1143-8. Epub 2004/07/22.

[5] Koch CG, Khandwala F, Li L, Estafanous FG, Loop FD, Blackstone EH. Persistent effect of red cell transfusion on health-related quality of life after cardiac surgery. The Annals of thoracic surgery. 2006;82(1):13-20. Epub 2006/06/27.

[6] Monroe DM, Hoffman M, Roberts HR. Fathers of modern coagulation. Thrombosis and haemostasis. 2007;98(1):3-5. Epub 2007/06/29.

[7] Riddel JP, Jr., Aouizerat BE, Miaskowski C, Lillicrap DP. Theories of blood coagulation. Journal of pediatric oncology nursing : official journal of the Association of Pediatric Oncology Nurses. 2007;24(3):123-31. Epub 2007/05/04.

[8] Curry AN, Pierce JT. Conventional and near-patient tests of coagulation. Continuing Education in Anaesthesia, Critical Care \& Pain. 2007;7(2):45-50.

[9] Bombeli T, Spahn DR. Updates in perioperative coagulation: physiology and management of thromboembolism and haemorrhage. British journal of anaesthesia. 2004;93(2):275-87. Epub 2004/06/29.

[10] Chan MY, Andreotti F, Becker RC. Hypercoagulable states in cardiovascular disease. Circulation. 2008;118(22):2286-97. Epub 2008/11/26.

[11] Platt A. Can you recognize a patient at risk for a hypercoagulable state? JAAPA : official journal of the American Academy of Physician Assistants. 2008;21(12):20-6. Epub 2009/03/04.

[12] Martel N, Lee J, Wells PS. Risk for heparin-induced thrombocytopenia with unfractionated and low-molecular-weight heparin thromboprophylaxis: a metaanalysis. Blood. 2005;106(8):2710-5. Epub 2005/06/30.

[13] van Ryn J, Stangier J, Haertter S, Liesenfeld KH, Wienen W, Feuring M, et al. Dabigatran etexilate--a novel, reversible, oral direct thrombin inhibitor: 
interpretation of coagulation assays and reversal of anticoagulant activity. Thrombosis and haemostasis. 2010;103(6):1116-27. Epub 2010/03/31.

[14] Di Nisio M, Middeldorp S, Buller HR. Direct thrombin inhibitors. The New England journal of medicine. 2005;353(10):1028-40. Epub 2005/09/09.

[15] Agnelli G, Eriksson BI, Cohen AT, Bergqvist D, Dahl OE, Lassen MR, et al. Safety assessment of new antithrombotic agents: lessons from the EXTEND study on ximelagatran. Thrombosis research. 2009;123(3):488-97. Epub 2008/05/20.

[16] Walenga JM, Jeske WP, Samama MM, Frapaise FX, Bick RL, Fareed J. Fondaparinux: a synthetic heparin pentasaccharide as a new antithrombotic agent. Expert opinion on investigational drugs. 2002;11(3):397-407. Epub 2002/02/28.

[17] Acostamadiedo JM, Iyer UG, Owen J. Danaparoid sodium. Expert opinion on pharmacotherapy. 2000;1(4):803-14. Epub 2001/03/16.

[18] Magnani HN, Gallus A. Heparin-induced thrombocytopenia (HIT). A report of 1,478 clinical outcomes of patients treated with danaparoid (Orgaran) from 1982 to mid2004. Thrombosis and haemostasis. 2006;95(6):967-81. Epub 2006/05/30.

[19] Ansell J, Hirsh J, Poller L, Bussey H, Jacobson A, Hylek E. The pharmacology and management of the vitamin $\mathrm{K}$ antagonists: the Seventh ACCP Conference on Antithrombotic and Thrombolytic Therapy. Chest. 2004;126(3 Suppl):204S-33S. Epub 2004/09/24.

[20] Salem DN, O'Gara PT, Madias C, Pauker SG. Valvular and structural heart disease: American College of Chest Physicians Evidence-Based Clinical Practice Guidelines (8th Edition). Chest. 2008;133(6 Suppl):593S-629S. Epub 2008/07/24.

[21] Vahanian A, Baumgartner H, Bax J, Butchart E, Dion R, Filippatos G, et al. Guidelines on the management of valvular heart disease: The Task Force on the Management of Valvular Heart Disease of the European Society of Cardiology. European heart journal. 2007;28(2):230-68. Epub 2007/01/30.

[22] Keeling D, Baglin T, Tait C, Watson H, Perry D, Baglin C, et al. Guidelines on oral anticoagulation with warfarin - fourth edition. British journal of haematology. 2011. Epub 2011/06/16.

[23] Dunning J, Versteegh M, Fabbri A, Pavie A, Kolh P, Lockowandt U, et al. Guideline on antiplatelet and anticoagulation management in cardiac surgery. European journal of cardio-thoracic surgery : official journal of the European Association for Cardiothoracic Surgery. 2008;34(1):73-92. Epub 2008/04/01.

[24] Storey RF. Pharmacology and clinical trials of reversibly-binding P2Y12 inhibitors. Thrombosis and haemostasis. 2011;105 Suppl 1:S75-81. Epub 2011/04/12.

[25] Landymore RW, Murphy JT, Lummis H, Carter C. The use of low-dose aprotinin, epsilon-aminocaproic acid or tranexamic acid for prevention of mediastinal bleeding in patients receiving aspirin before coronary artery bypass operations. European journal of cardio-thoracic surgery : official journal of the European Association for Cardio-thoracic Surgery. 1997;11(4):798-800. Epub 1997/04/01.

[26] Bidstrup BP, Hunt BJ, Sheikh S, Parratt RN, Bidstrup JM, Sapsford RN. Amelioration of the bleeding tendency of preoperative aspirin after aortocoronary bypass grafting. The Annals of thoracic surgery. 2000;69(2):541-7. Epub 2000/03/29.

[27] Mangano DT, Tudor IC, Dietzel C. The risk associated with aprotinin in cardiac surgery. The New England journal of medicine. 2006;354(4):353-65. Epub 2006/01/27. 
[28] Sedrakyan A, Treasure T, Elefteriades JA. Effect of aprotinin on clinical outcomes in coronary artery bypass graft surgery: a systematic review and meta-analysis of randomized clinical trials. The Journal of thoracic and cardiovascular surgery. 2004;128(3):442-8. Epub 2004/09/09.

[29] Henry D, Carless P, Fergusson D, Laupacis A. The safety of aprotinin and lysinederived antifibrinolytic drugs in cardiac surgery: a meta-analysis. CMAJ : Canadian Medical Association journal = journal de l'Association medicale canadienne. 2009;180(2):183-93. Epub 2008/12/04.

[30] Slichter SJ. Evidence-based platelet transfusion guidelines. Hematology / the Education Program of the American Society of Hematology American Society of Hematology Education Program. 2007:172-8. Epub 2007/11/21.

[31] Wall MH, Prielipp RC. Transfusion in the operating room and the intensive care unit: current practice and future directions. International anesthesiology clinics. 2000;38(4):149-69. Epub 2000/12/02.

[32] Karlsson M, Ternstrom L, Hyllner M, Baghaei F, Nilsson S, Jeppsson A. Plasma fibrinogen level, bleeding, and transfusion after on-pump coronary artery bypass grafting surgery: a prospective observational study. Transfusion. 2008;48(10):21528. Epub 2008/07/29.

[33] Ucar HI, Oc M, Tok M, Dogan OF, Oc B, Aydin A, et al. Preoperative fibrinogen levels as a predictor of postoperative bleeding after open heart surgery. The heart surgery forum. 2007;10(5):E392-6. Epub 2007/09/15.

[34] Karlsson M, Ternstrom L, Hyllner M, Baghaei F, Flinck A, Skrtic S, et al. Prophylactic fibrinogen infusion reduces bleeding after coronary artery bypass surgery. A prospective randomised pilot study. Thrombosis and haemostasis. 2009;102(1):13744. Epub 2009/07/03.

[35] Volzke H, Robinson DM, Kleine V, Hertwig S, Schwahn C, Grimm R, et al. Preoperative plasma fibrinogen levels predict mortality after coronary artery bypass grafting. Thrombosis and haemostasis. 2003;89(5):885-91. Epub 2003/04/30.

[36] Fries D, Martini WZ. Role of fibrinogen in trauma-induced coagulopathy. British journal of anaesthesia. 2010;105(2):116-21. Epub 2010/07/16.

[37] Hiippala ST, Myllyla GJ, Vahtera EM. Hemostatic factors and replacement of major blood loss with plasma-poor red cell concentrates. Anesthesia and analgesia. 1995;81(2):360-5. Epub 1995/08/01.

[38] Rahe-Meyer N, Pichlmaier M, Haverich A, Solomon C, Winterhalter M, Piepenbrock S, et al. Bleeding management with fibrinogen concentrate targeting a high-normal plasma fibrinogen level: a pilot study. British journal of anaesthesia. 2009;102(6):785-92. Epub 2009/05/05.

[39] Humphries SE, Luong LA, Montgomery HE, Day IN, Mohamed-Ali V, Yudkin JS. Gene-environment interaction in the determination of levels of plasma fibrinogen. Thrombosis and haemostasis. 1999;82(2):818-25. Epub 1999/12/22.

[40] Lier H, Krep H, Schroeder S, Stuber F. Preconditions of hemostasis in trauma: a review. The influence of acidosis, hypocalcemia, anemia, and hypothermia on functional hemostasis in trauma. The Journal of trauma. 2008;65(4):951-60. Epub 2008/10/14.

[41] Koch CG, Li L, Sessler DI, Figueroa P, Hoeltge GA, Mihaljevic T, et al. Duration of redcell storage and complications after cardiac surgery. The New England journal of medicine. 2008;358(12):1229-39. Epub 2008/03/21. 
[42] Luddington RJ. Thrombelastography/thromboelastometry. Clinical and laboratory haematology. 2005;27(2):81-90. Epub 2005/03/24.

[43] Srinivasa V, Gilbertson LI, Bhavani-Shankar K. Thromboelastography: where is it and where is it heading? Int Anesthesiol Clin. 2001;39(1):35-49. Epub 2001/04/05.

[44] Craft RM, Chavez JJ, Bresee SJ, Wortham DC, Cohen E, Carroll RC. A novel modification of the Thrombelastograph assay, isolating platelet function, correlates with optical platelet aggregation. J Lab Clin Med. 2004;143(5):301-9. Epub 2004/05/04.

[45] Bochsen L, Wiinberg B, Kjelgaard-Hansen M, Steinbruchel DA, Johansson PI. Evaluation of the TEG platelet mapping assay in blood donors. Thromb J. 2007;5:3. Epub 2007/02/22.

[46] Solomon C, Pichlmaier U, Schoechl H, Hagl C, Raymondos K, Scheinichen D, et al. Recovery of fibrinogen after administration of fibrinogen concentrate to patients with severe bleeding after cardiopulmonary bypass surgery. British journal of anaesthesia. 2010;104(5):555-62. Epub 2010/03/30.

[47] Shore-Lesserson L, Manspeizer HE, DePerio M, Francis S, Vela-Cantos F, Ergin MA. Thromboelastography-guided transfusion algorithm reduces transfusions in complex cardiac surgery. Anesth Analg. 1999;88(2):312-9. Epub 1999/02/11.

[48] Spiess BD, Tuman KJ, McCarthy RJ, DeLaria GA, Schillo R, Ivankovich AD. Thromboelastography as an indicator of post-cardiopulmonary bypass coagulopathies. J Clin Monit. 1987;3(1):25-30. Epub 1987/01/01.

[49] Spiess BD, Gillies BS, Chandler W, Verrier E. Changes in transfusion therapy and reexploration rate after institution of a blood management program in cardiac surgical patients. J Cardiothorac Vasc Anesth. 1995;9(2):168-73. Epub 1995/04/01.

[50] Tuman KJ, Spiess BD, McCarthy RJ, Ivankovich AD. Comparison of viscoelastic measures of coagulation after cardiopulmonary bypass. Anesth Analg. 1989;69(1):69-75. Epub 1989/07/01.

[51] Avidan MS, Alcock EL, Da Fonseca J, Ponte J, Desai JB, Despotis GJ, et al. Comparison of structured use of routine laboratory tests or near-patient assessment with clinical judgement in the management of bleeding after cardiac surgery. Br J Anaesth. 2004;92(2):178-86. Epub 2004/01/15.

[52] Westbrook AJ, Olsen, J., Bailey, M., Bates, J., Scully, M., Salamonsen, R.F. Protocol based on thromboelastograph (TEG) out-performs physician preference using laboratory coagulation tests to guide blood replacement during and after cardiac surgery: a pilot study. Heart Lung and Circulation \{Manuscript number: HLC-D-08-00027R1 Heart Lung and Circulation (in press)\}. 2008.

[53] Marik PE, Corwin HL. Efficacy of red blood cell transfusion in the critically ill: a systematic review of the literature. Critical care medicine. 2008;36(9):2667-74. Epub 2008/08/06.

[54] Engoren MC, Habib RH, Zacharias A, Schwann TA, Riordan CJ, Durham SJ. Effect of blood transfusion on long-term survival after cardiac operation. The Annals of thoracic surgery. 2002;74(4):1180-6. Epub 2002/10/29.

[55] Ferraris VA, Brown JR, Despotis GJ, Hammon JW, Reece TB, Saha SP, et al. 2011 update to the Society of Thoracic Surgeons and the Society of Cardiovascular Anesthesiologists blood conservation clinical practice guidelines. The Annals of thoracic surgery. 2011;91(3):944-82. Epub 2011/03/01. 
[56] de Jonge E, Levi M. Effects of different plasma substitutes on blood coagulation: a comparative review. Critical care medicine. 2001;29(6):1261-7. Epub 2001/06/08.

[57] Van der Linden P, Ickx BE. The effects of colloid solutions on hemostasis. Canadian journal of anaesthesia = Journal canadien d'anesthesie. 2006;53(6 Suppl):S30-9. Epub 2006/06/13.

[58] de Jonge E, Levi M, Berends F, van der Ende AE, ten Cate JW, Stoutenbeek CP. Impaired haemostasis by intravenous administration of a gelatin-based plasma expander in human subjects. Thrombosis and haemostasis. 1998;79(2):286-90. Epub 1998/03/11.

[59] Hartog CS, Bauer M, Reinhart K. The efficacy and safety of colloid resuscitation in the critically ill. Anesthesia and analgesia. 2011;112(1):156-64. Epub 2010/12/04. 


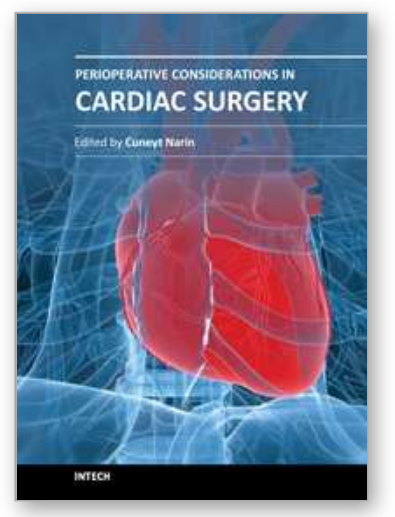

\author{
Perioperative Considerations in Cardiac Surgery \\ Edited by Prof. Cuneyt Narin
}

ISBN 978-953-51-0147-5

Hard cover, 378 pages

Publisher InTech

Published online 29, February, 2012

Published in print edition February, 2012

This book considers mainly the current perioperative care, as well as progresses in new cardiac surgery technologies. Perioperative strategies and new technologies in the field of cardiac surgery will continue to contribute to improvements in postoperative outcomes and enable the cardiac surgical society to optimize surgical procedures. This book should prove to be a useful reference for trainees, senior surgeons and nurses in cardiac surgery, as well as anesthesiologists, perfusionists, and all the related health care workers who are involved in taking care of patients with heart disease which require surgical therapy. I hope these internationally cumulative and diligent efforts will provide patients undergoing cardiac surgery with meticulous perioperative care methods.

\title{
How to reference
}

In order to correctly reference this scholarly work, feel free to copy and paste the following:

Philip Johnson and Andrew Westbrook (2012). Coagulation Measurement and Optimisation in Cardiac Surgery, Perioperative Considerations in Cardiac Surgery, Prof. Cuneyt Narin (Ed.), ISBN: 978-953-51-0147-5, InTech, Available from: http://www.intechopen.com/books/perioperative-considerations-in-cardiacsurgery/coagulation-measurement-and-optimisation-in-cardiac-surgery

\section{INTECH}

open science | open minds

\section{InTech Europe}

University Campus STeP Ri

Slavka Krautzeka 83/A

51000 Rijeka, Croatia

Phone: +385 (51) 770447

Fax: +385 (51) 686166

www.intechopen.com

\section{InTech China}

Unit 405, Office Block, Hotel Equatorial Shanghai

No.65, Yan An Road (West), Shanghai, 200040, China

中国上海市延安西路65号上海国际贵都大饭店办公楼405单元

Phone: +86-21-62489820

Fax: $+86-21-62489821$ 
(C) 2012 The Author(s). Licensee IntechOpen. This is an open access article distributed under the terms of the Creative Commons Attribution 3.0 License, which permits unrestricted use, distribution, and reproduction in any medium, provided the original work is properly cited. 